Article

\title{
Gloss, Light Reflection and Iridescence in Ceramic Tile Enamels Containing $\mathrm{ZrO}_{2}$ and $\mathrm{ZnO}$
}

\author{
Víctor Echarri-Iribarren *(1) and Carlos Rizo-Maestre $(1)$ \\ Department of Building Construction, University of Alicante, 03690 San Vicente, Spain; carlosrm@ua.es \\ * Correspondence: Victor.Echarri@ua.es; Tel.: +34-965-903677
}

Received: 29 July 2020; Accepted: 26 August 2020; Published: 1 September 2020

\begin{abstract}
Ceramic claddings on building facades not only present functional qualities and good resistance; they also add value to the architecture due to their qualities of light reflection, gloss and iridescence. The colour ranges produced by some enamel application techniques can vary widely. They change depending on one's angle of vision and movement, colours in the surroundings, sunlight and their angle of incidence. In addition, the iridescent-pearl effect produced by light diffraction can lead to beautiful goniochromatic colours. This study analyses the production of square tiles of stoneware manufactured by extrusion, and their application to the Faculty of Education of the University of Alicante (FEUA) (Spain). Applying an enamel containing zirconium silicate $\mathrm{ZrSiO}_{4}$ and other metals such as $\mathrm{Zn}$ and $\mathrm{Al}$ produces iridescence-like effects. The physical-chemical properties of enamel and gloss values were characterised. A colorimetric characterisation was conducted by evaluating goniochromatic or iridescent colours, measuring the light's spectral radiance factor, and comparing these results with other ceramic tiles of marked iridescent effects, with the presence of a final layer of anatase $\mathrm{TiO}_{2}$ enamel.
\end{abstract}

Keywords: ceramics; zirconium; glitter; iridescent-pearling; iridescence; metal deposition; reflectance; goniochromatic colours

\section{Introduction}

In recent decades, the ceramics industry has undergone a renewal, regaining its innovative and technological nature. After a period of being applied almost exclusively to bathrooms and kitchens, porcelain stoneware and enamelled ceramics are now also being used for cladding, especially on building facades [1]. This recovery has led to further developments of construction solutions that use ceramics to meet new functional, aesthetic and economic requirements in architecture [2]. Ceramics have been consolidated as a versatile material [3] thanks to research in both manufacturing and post-manufacturing processes.

A permanent field of research in ceramics is the improvement of mechanical and resistance properties. With porcelain stoneware, ceramic building claddings have achieved remarkable outcomes both in press and extrusion manufacturing. Today, the emergence of graphene is producing promising results regarding mechanical resistance. Ahmad et al. reinforce ceramics with carbon nanostructures (CNTs and graphene). They have successfully enhanced the toughness and other properties of brittle ceramics and converted them into useful materials for next generation applications [4]. This is certainly a priority line of exploration for building applications. Chen et al. applied nanoparticles coated with $\mathrm{SiO}_{2}$ to improve $\mathrm{Al}_{2} \mathrm{O}_{3} / \mathrm{TiC}$ self-lubricating ceramic composites, increasing anti-friction and mechanical strength by more than $15 \%$ [5]. Ceramics are also experiencing important advances as a refractory material, with possible applications in construction. Giuranno et al. provide refractory composites based on zirconium disilicide $\mathrm{ZrSi}_{2}$ [6], and Villalba et al. refractory bricks containing mullite-zirconia composites [7]. 
This innovation agenda is also linked to the relationship between ceramic finishes and light. Light reflection and refraction have been analysed and enhanced using new enamel techniques, whether via chemical composition, firing techniques or physical application over various layers. This study focuses on the iridescence of the ceramic tiles that cover the entrance to the Faculty of Education building of the University of Alicante (FEUA), which was recently renovated in 2018. One of the $9 \mathrm{~mm}$ thick, $20 \times 20 \mathrm{~cm}$ square ceramic tiles was analysed using X-ray diffraction techniques and a scanning electron microscope. We characterised the enamels applied to the inner and outer coatings via vitrification and deposition of metals, determining the physical-chemical properties and factors that produce iridescent-like effects when sunlight is reflected. Finally, a colorimetric characterisation of the tiles' finishing enamels was performed. We evaluated the gloss levels and the goniochromatic or iridescent colours, measured the light's spectral radiance factor and compared the results with that of other ceramic, markedly iridescent tiles [8].

\subsection{Light Transmittance, Gloss and Luminescence in Ceramics}

Research efforts have increased in recent decades to improve colour transmittance and performance as well as to enhance gloss in industrial processes. Its presence is mainly produced for decorative purposes, in paint finishes and in other metal or ceramic surface finishes, or in aluminium oxide films for electronical devices. Techniques abound and are wide-ranging. In the case of anodic aluminium oxide (AAO) films, $\mathrm{Xu}$ et al. propose the deposition of magnetic Ni metals (nickel), which cover the film's pores, while generating optical and iridescent colour properties for applications in multifunctional anti-counterfeit technology and electronical devices [9]. With the orientation of NiCo nanowire particles, excellent optical, electrical and magnetic properties are achieved, substantially enhancing the bright structural colours with reflectance spectrum test generating consistent results [10]. In contrast to pigmentary colours attributed to the selective absorption of light, structural colours arise mostly from the interference of light in thin-layer or multilayer, which are considerably brighter. Wang et al. pursue better light reflection and refractive effects through an air-AAO interface, which often gives rise to a visible interference colour and increases gloss [11]. Li et al. obtained iridescent structural colours by applying self-assembled colloidal spheres similar to natural opal, with polythiurethane microspheres (PTUMS) [12]. In other cases, the goal is to eliminate iridescence, largely suppressing light diffraction by applying reduced graphene oxide (GO), obtaining non-iridescent structural colours [13].

There are a variety of techniques to treat light in ceramic enamels, producing a wide range of outcomes. The colour performance index (CRI) has been regularly improved [14]. Wu et al. apply phosphor-SiO ${ }_{2}$ and obtain good results for laser lighting with high luminous efficiency $(183 \mathrm{~lm} / \mathrm{W})$ and high gloss [15]. Rojas-Hernández et al. succeed in prolonging blue long-lasting luminescence in ceramic tiles, using calcium aluminates and the molten salt route, which could also be applied to building finishes [16]. The optical properties and light transmittance spectrum in transparent ceramics [17] can be improved with diamond particles. By removing intragranular pores with co-doped alumina in the microstructure of $\mathrm{SrHfO}_{3}: \mathrm{Ce}, \mathrm{Al}$, Quinag et al. improve ceramic light performance and thermoluminescence [18]. Using the Seger method, Mirdali et al. obtain crystalline layers with deposition of metal $\mathrm{Ag}$ and $\mathrm{Cu}$ particles in a reduction atmosphere. They produce an interesting low temperature enamel technique, with a bright multi-colour metallic effect [19].

The final aspect of ceramic tiles usually results from crystallisation, over various phases, leading to finishes that present various properties such as: gloss, opacity, anti-slip, roughness, lustre [20] or reflectance [21]. Other pursued phenomena are optical in nature, interacting with sunlight or artificial light with the various layers of enamel: zirconium oxide $\mathrm{ZrO}_{2}[22,23]$ and titanium oxide are widely used in this latter case. Pigments have sometimes been obtained that improve the reflection of light with metallic gloss, gold, solar reflectance effects [24] or phosphorescent effects [25]. Interesting results have also been reached via encapsulation techniques [26], by applying nanopigments [27], microemulsions or by inkjet printer [28]. 


\subsection{Iridescent and Pearl Techniques}

One of the most interesting effects found in ceramic finishes is the multicoloured effect or iridescence. Iridescence is among the most beautiful optical phenomena offered by certain minerals. According to this property, the light shade varies on certain surfaces depending on the user's angle of observation. This optical phenomenon is not due to its chemical composition or crystalline structure but to the interaction of light with certain inclusions or structural defects in the material.

Numerous patents regarding the production of iridescent effects have been developed in recent years [29]. Novel techniques are applied and substrates are adapted to various geometries and compositions, such as transparent films, organic adhesives, glass spheres, metal resins, etc. [30]. In the case of ceramic finishes, the most common techniques are metal depositions such as titanium [31], gold, silver, aluminium or zirconium $[32,33]$. The produced iridescence has various causes. It is sometimes due to the scattering of light [34] that causes white light to decompose into its different colours when it passes through a prism. Sometimes it is due to the interaction of light reflected by the different layers in semitransparent bilayer or multilayer structures. Iridescence can also be caused by light diffraction, a physical-optical phenomenon that is mainly due to the existence of irregularities encountered by light in its path, such as cavities of a similar size to that of the wavelength of light that is diffracted. White light sometimes passes through these small spaces, pores or microcracks. In other cases, it crosses thin layers of material presenting a variable refractive index, inducing the separation of white light into the entire colour spectrum. Wavelengths interfere with each other causing iridescence. The iridescent effect produced by enamels melted with Cu nanoparticles with sang de boeuf (ox blood) is studied by Sciau et al., concluding that the production of a multilayer microstructure favours the effect of iridescent reflection, and the colour comes only from Cu particles [35].

Other treatments related to iridescence include pearling and the use of pearl pigments [36,37]. Pearl pigments of anatase $\left(\mathrm{TiO}_{2}\right)$ [38], laid on the ceramic substrate, are usually applied with subsequent calcination. The substrates on which $\mathrm{TiO}_{2}$ is applied are natural mica (muscovite), synthetic mica (fluorphlogopite) or alpha-alumina flakes [39]. Techniques for applying $\mathrm{CeO}_{2}$ cerium oxide deposition are also efficient to obtain pearl effects, which also present iridescence [40]. When combined with other metals, a softer pearly effect can be produced. Other alternative techniques may generate effects in ceramics that resemble iridescence and pearling, such as the use of titanium and cobalt $\left(\mathrm{TiO}_{2} @ \mathrm{CoAl}_{2} \mathrm{O}_{4}\right)$ [41] for bright colours [42], zirconium pigments encapsulated with deep black colours [43], or zinc oxide-based iridescent metallic effect surfaces $(\mathrm{ZnO})$ [44]. Some recent research has shown iridescent and pearl effects based on enamels containing zinc oxide, zirconium oxide, itrio oxide, titanium oxide, hafnium oxide and cerium oxide [45].

\subsection{Objectives}

Previous research has allowed to determine the factors that produce iridescent effects in ceramic tiles laid out on building facades. In the case of the Auditorium of Algueña (Casa de la Música y Auditorio de la Algueña, or MUCA) in Alicante (Spain), several enamels were applied over four firing and manufacturing phases. The result allowed to conclude that distributing dispersed zirconium on the surface favours iridescence. A final application of anatase in the third firing phase produced microscopic cracks, multiplying the effect of iridescence [8]. In the case of the headquarters building of the Botín Foundation in Santander (Spain), the spherical cap-shaped ceramic pieces were fired twice during the manufacturing: first with a white enamel base, and second with depositions of zirconium oxide and zinc oxide metals. The last layer of anatase-present in the ceramic tiles of the MUCA-was not applied, resulting in lesser iridescence [46].

This study focused on the comparative analysis of the ceramic tiles used in the renovation of the FEUA, and their relationship with light. To this end, the physical-chemical composition of the enamels was analysed, and some colorimetric and gloss parameters were quantified, with the following objectives: 
- To determine whether they have iridescent properties, due to light diffraction, or, conversely, whether they only present gloss effects and the reflection of light with elements in the surroundings.

- To determine the factors that produce the tiles' high capacity for light reflection, reproduction and colour variety.

- To compare the colorimetric and gloss analysis to that of the ceramic pieces found on the façade of the Algueña Auditorium (MUCA).

\section{Materials and Methods}

The objectives set forth in this study required a rigorous analysis of the different layers of enamel on the ceramic pieces. The various phenomena of solar irradiation, reflection and diffraction of light also needed to be analysed. To this end, a four-phase structured analysis methodology was designed:

1. Physico-chemical analysis of the bases and various enamel layers of the ceramic pieces. The goal was to determine the factors that produce the phenomena of gloss, reflection, iridescence and light diffraction. It was essential to characterise the layers' various metals, distribution and possible microcracks. The physical-chemical characterisation of the analysed ceramic materials was performed using X-ray diffraction (XRD, Bruker D8-Advance, Alicante, Valencian State, Spain) and scanning electron microscopy (SEM, Hitachi S3000N, Alicante, Valencian State, Spain).

1.1. X-ray diffraction (XRD) is based on optical interference that occurs when monochrome radiation passes through a slit that has a thickness similar to that of the radiation wavelength. When irradiated over the sample to be analysed, the X-rays diffract at various angles depending on interatomic distances, thus allowing to identify the mineralogical composition of the crystalline samples. The equipment used in Alicante university's technical services is a Bruker D8-Advance with a high temperature camera (up to $900{ }^{\circ} \mathrm{C}$ ), and a KRISTALLOFLEX K 760-80F X-ray generator, equipped with an RX tube with a copper anode. The analysis was conducted in two phases, the first for a $2 \theta$ angle scanning between $25^{\circ}-113^{\circ}$, and the second between $3^{\circ}-70^{\circ}$, and a step of $0.05^{\circ}$.

1.2. Scanning electron microscopy (SEM) allows to identify the elements present in the sample and establish their concentration through the X-rays generated after electronic bombardment. The equipment used at the University of Alicante is a Hitachi S3000N model scanning electron microscope, which features a Bruker XFlash $3001 \mathrm{X}$-ray detector for microanalysis (EDS) and mapping. This SEM is equipped with an energy-dispersive X-ray spectrometry (EDX), a dispersive energy detector that allows you to collect the $\mathrm{X}$-rays generated by the sample and perform various analyses. This allows obtaining images of the element distribution on polished surfaces.

2. Colorimetric characterisation. The objective was to analyse the goniochromatic colours and the various colour ranges on the enamelled faces of the ceramic tiles under study when subjected to light. The characterisation was performed based on observer perceptions according to viewing position and angle. We thus aimed at assessing the results of the gloss and iridescence effect pursued during the manufacturing of the ceramic pieces.

The colorimetric study was mainly performed using a multi-angle spectrophotometer, of the brand/model BYK-mac i 23 mm (BYK-Gardner GmbH, Alicante, Valencian State, Spain) (Figure 1). It consisted of a configuration of the measurement of light reflected in various directions of the light's incidence and reception, or measuring geometries, in accordance with the ASTM E2194 standard [47], typically used in goniochromatic colours [48] for the automotive sector [49], as well as in cosmetics and other industrial sectors. To measure the colour, the light is set at a $45^{\circ}$ angle of incidence on the sample, and the reflected light is determined in six angular positions (Figure 1). This is known as six different measurement geometries. 


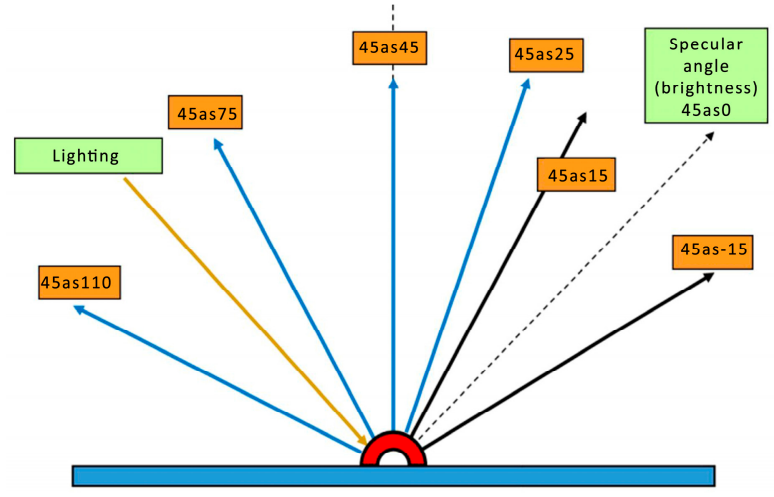

(a)

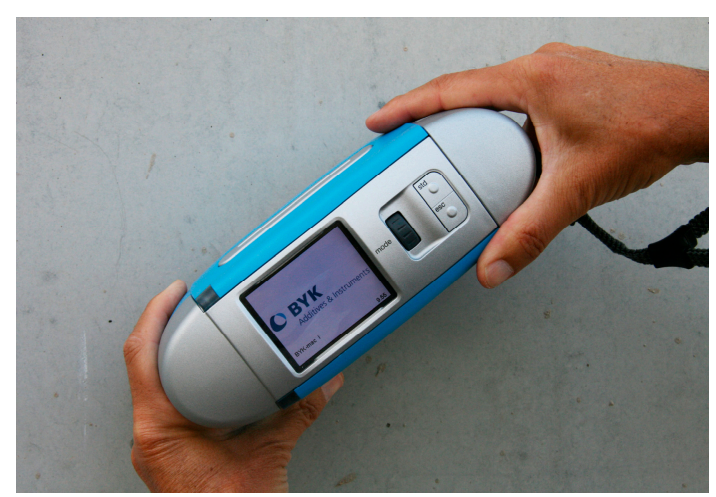

(b)

Figure 1. Colorimetry geometries (a) and multi-angle instrument used (b).

3. Characterisation of the behaviour of gloss before the incidence of light, observers' visual perception produced during the different daily and annual phases. The behaviour of the enamelled sides had to be measured according to the light coming from various angles, the quality of gloss of these enamels, the ability to reproduce the colour of elements or objects in the immediate surroundings of the enamel façade. For this purpose, the Minolta Multi-Gloss 268 equipment was made available by the University Institute of Physics Applied to Sciences and Technologies (IUFACyT) of the University of Alicante. The spectral radiance factor, or reflectance, was determined for each measurement geometry, and the chromatic coordinates in the CIE- $L^{*}{ }^{*} b^{*}$ space under D65 illumination (daylight) were calculated based on it. The reflectance of the ceramic samples could thus be displayed for the 6 different measurement geometries. Spectral measurements of characteristic colours [50] were analysed by tilting around the spectral profile and geometries closest to the direction of the gloss.

4. A comparative analysis of the results obtained in the previous test stages were made. It was important to evaluate the above parameters in each phase according to the manufacturing and enamel process of the ceramic tiles of both buildings. This way, it was possible to determine the factors that produce the effects of reflection, diffraction and iridescence of light making it possible to meet the study's proposed objectives.

\section{Faculty of Education of the University of Alicante: Ceramics and Reflection of Light}

The Faculty of Education of the University of Alicante (FEUA) has recently been renovated. The building is located on the campus of the university of San Vicente del Raspeig (Alicante). It has a built surface area of $1820 \mathrm{~m}^{2}$, and it consists of twin volumes, a ground floor plus a first floor. Its construction is based on masonry walls clad with single-layer mortar, a reinforced concrete structure and a hip roof with Spanish roof tiles. During the renovation, two small new volumes were added to the two building entrances, in the south and north facades. They are covered with ceramic pieces presenting a high level of light reflection, with iridescent-like effects.

These two units resemble two cubes, their sides measuring approximately $6.80 \mathrm{~m}$. The cube on the south façade is lined with $20 \times 20 \mathrm{~cm}$ soft grey glazed ceramic pieces (Figure 2). Their function is that of the building's entrance hall, and heat pumps for the building's air conditioning are housed in their rooves. They are hidden by the parapet.

The cube provides a touch of colour to the whole, on the façade's white monolayer, and the ceramic generates a wide variety of light effects via the highly reflective enamels applied to the visible faces (Figure 3). Depending on the time of year and day, the façade faces can reflect a broad range of colours coming from elements in the surroundings. The ceramic tiles lack flatness because the grey enamel layer was applied using a brush. Thanks to this, the effect of light vibration is enhanced at 
certain times during the day, leading to visual perceptions of iridescent-like effects. Solar radiation, common in Alicante's climate, reinforces these lighting effects.

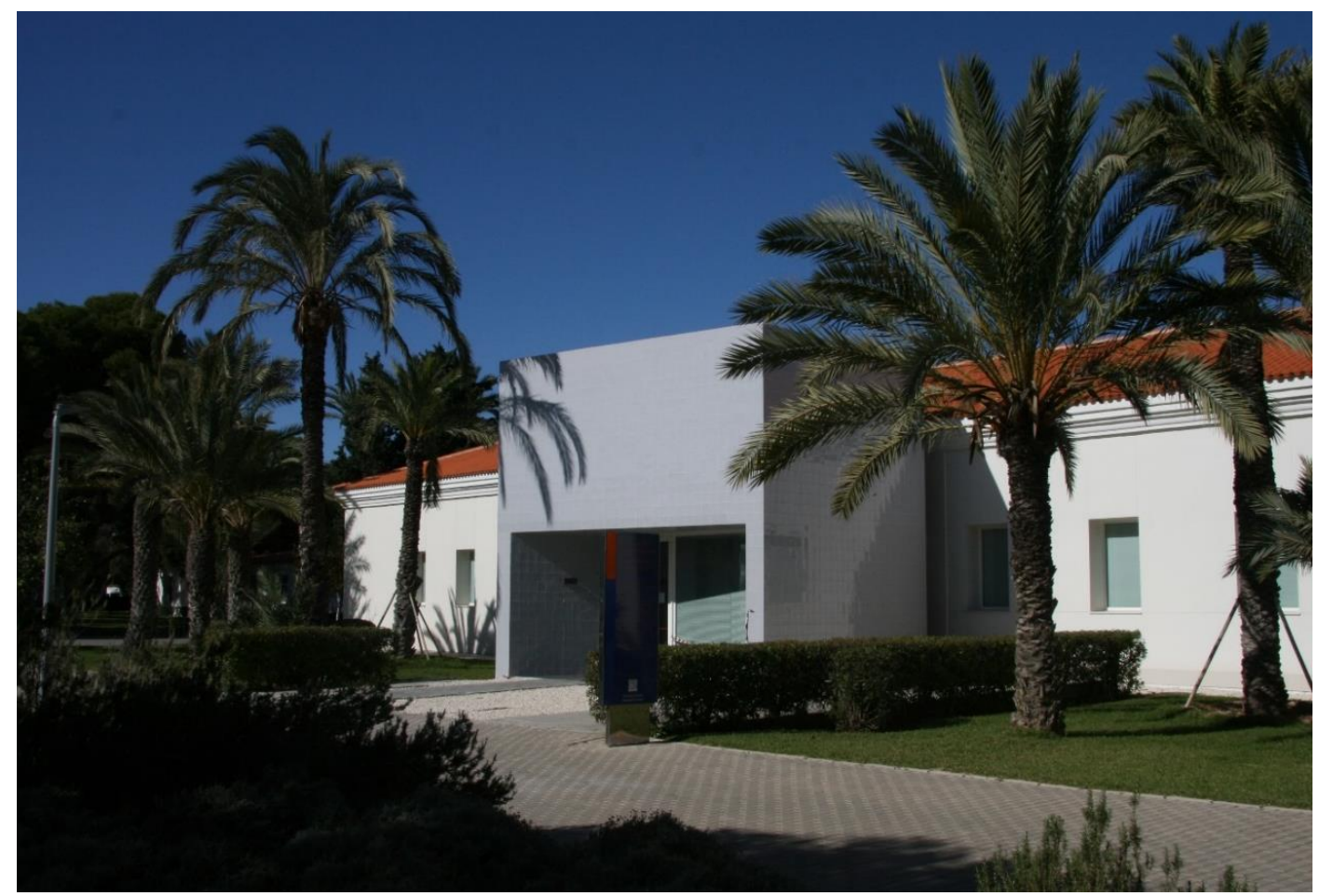

Figure 2. Faculty of Education of the University of Alicante (FEUA). Access cube covered with ceramic pieces.

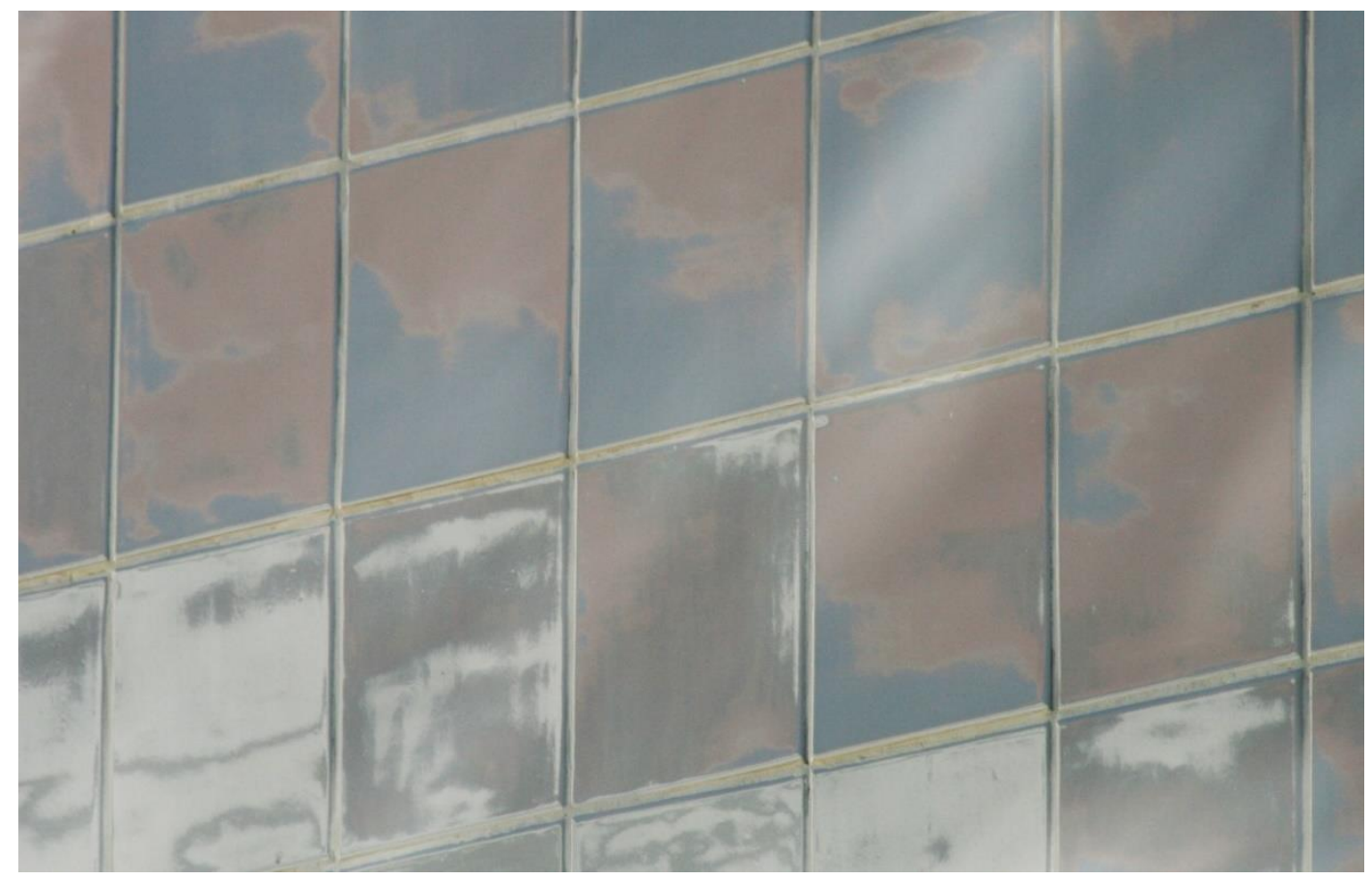

Figure 3. FEUA. Chromatic range of light reflection and iridescence in ceramic tiles.

\section{Description of the Manufacturing Process}

The ceramic tiles used in the FEUA building were developed on ceramic pastes stoned at high temperatures, of approximately $1000{ }^{\circ} \mathrm{C}$. Using the techniques described below, it was possible to 
achieve the technical qualities, associated with an effect of light reflection resembling iridescence, and the quality required in the field of architecture for claddings particularly resistant to weather.

The volumes with an exterior ceramic coating corresponded to a widely used coating validated by numerous previous architectural works. The ceramic tiles were $20 \times 20 \mathrm{~cm}$ square-shaped pieces $10 \mathrm{~mm}$ thick. They are red paste stoneware, with a water absorption of 3-3.5\%, produced by extrusion. Their enamel layer over a slip layer beneath makes them waterproof. The joining material ensures low rainwater absorption on the edges of the tiles.

These ceramic enamelled stoneware tiles can be manufactured by press or extrusion. The press manufacturing technique was not applied to avoid an excessively flat finishing surface. Indeed, the use of $25 \mathrm{Tm}$ hydraulic presses, with an applied pressure of $62 \mathrm{~kg} / \mathrm{cm}^{2}$, followed by a polishing treatment to remove the atomised dust particles that remain on the surface before applying the slip and enamels leads to a remarkably flat finish. The subsequent light reflection effect on the building's cladding is usually homogeneous. This effect was not the one that was sought.

Instead, the extrusion technique was used to make the biscuit. This means the paste contains higher levels of moisture, and its linear geometry can be shaped when passing through the nozzle. Square parts, measuring the same width as the extrusion exit bandwidth, are cut according to a template. They are then placed in a continuous dryer to reduce their humidity, thus doubling or tripling their mechanical strength and allowing them to undergo subsequent processing. The enamel is applied at a later stage, allowing to reach a level of gloss and smooth texture that generate the targeted light reflection effects. To start with, these applied enamels undergo a biscuit phase that enables removing certain organic matter, if there is any, or simply facilitating the enamel's handling processes. This latter stage applies in particular in the case of special parts, in terms both of structure fragility and size. After manually applying silica-based enamels, a less homogeneous and above all less flat surface is achieved than during press manufacturing. During the firing process at $1000{ }^{\circ} \mathrm{C}$, which lasts about $45 \mathrm{~min}$, the silica melts into the varnish and is perfectly associated with the base of the biscuit, which presents irregularities in its flatness.

To summarise, these square ceramic tiles with iridescent-like gloss effects are achieved over a five-phase process:

Phase 1: Geometric production of the semi-craftsmanship tile by extrusion (Figure 4).

Phase 2; Introduction into a continuous dryer to reduce the moisture in the paste.

Phase 3: Application of a slip layer to generate an interface between the biscuit and the enamel, which minimises the tension between the two layers due to differences in dilation coefficients and post-cooling contraction.

Phase 4: Application of enamel using any of the usual methods: bell-shaped system, airbrush, disc glazing, spraying.

Phase 5: Firing. Biscuits of ceramic $20 \times 20 \mathrm{~cm}$ stoneware tiles, with mono-firing system at $950{ }^{\circ} \mathrm{C}$ to vitrify the biscuit and the ceramic piece's protective enamel.

In this way, the reflection of light on the tiles produces vibration effects as well as formal and geometric variations as users vary their angles of vision, or simply approach and circulate through the building (Figure 5). Visual perception thus varies in space and over time, sometimes producing iridescence-like effects.

The process differs significantly, a priori, from that employed to make other porcelain stoneware with iridescent effects, such as those used in the MUCA. The ceramic is also produced based on ceramic pastes stoned at high temperatures, via semi-craftsmanship production. The iridescent effect is achieved through three successive firings:

Firing 1: Application of white-based enamel to vitrify the biscuit. Firing at $1180^{\circ} \mathrm{C}$. Initial ceramic pieces with white-based enamel are obtained for later phases.

Firing 2: Application of enamel with a titanium oxide, zirconium oxide and zinc oxide base. Manually applied with a brush. Firing at $1180^{\circ} \mathrm{C}$. Initial iridescence and pearl results are produced. 
Firing 3: Application mainly of titanium oxide-based enamel. Final coating between 0.5 and 1 micron. Firing at temperatures between 750 and $780^{\circ} \mathrm{C}$.

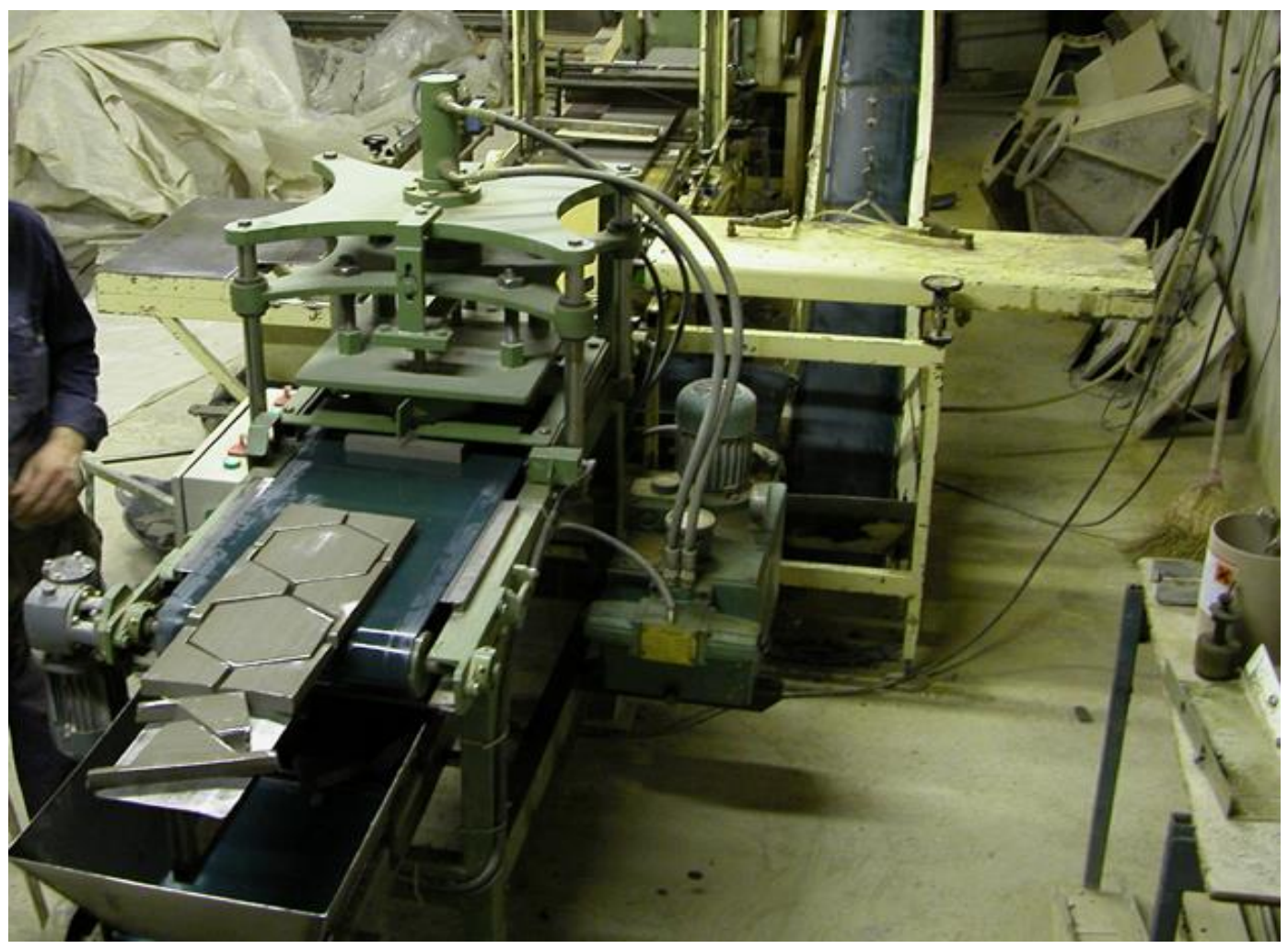

Figure 4. Cutting and shaping of the pieces after the extrusion process of the ceramic paste, prior to glazing and subsequent firing. Cumella Ceramics.

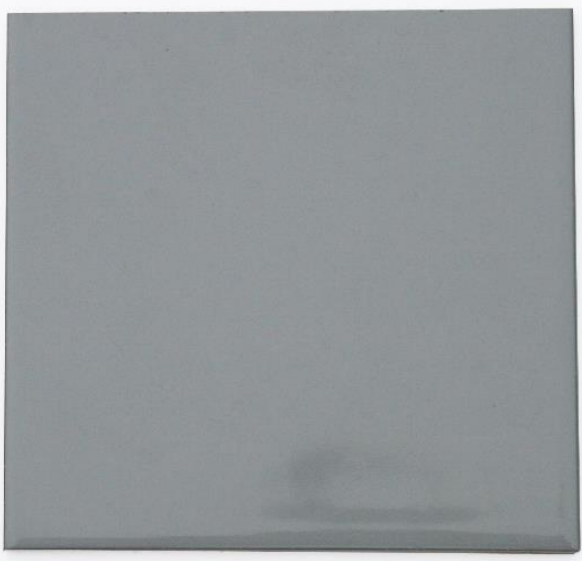

(a)

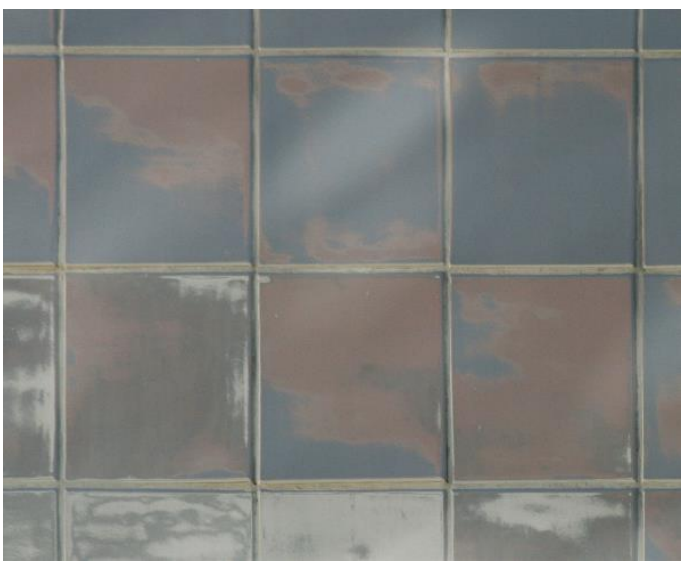

(b)

Figure 5. Ceramic tile of the FEUA. Sunlight incidence, iridescence and reflections of the surroundings. (a) The ceramic tile without solar light reflection effect; (b) The in situ ceramic tile at 12:00 am 26th June.

It is precisely before the third firing that the balm formed by solutions of metal salts in resins or other vehicles is applied to the vitrified enamels. Following the guidelines set out, some recent research carried out various eutectic combinations [51], which allow the obtaining of satisfactory structural results [52]. A coating manually applied with a brush based on titanium oxide, zirconium oxide and zinc oxide consists of particles with different dilation coefficients, and sizes between 50 and 
350 microns. The last vitrified layer is cracked, which multiplies the iridescent effects of the reflection of light, with colours and shades of colours (Figure 6).

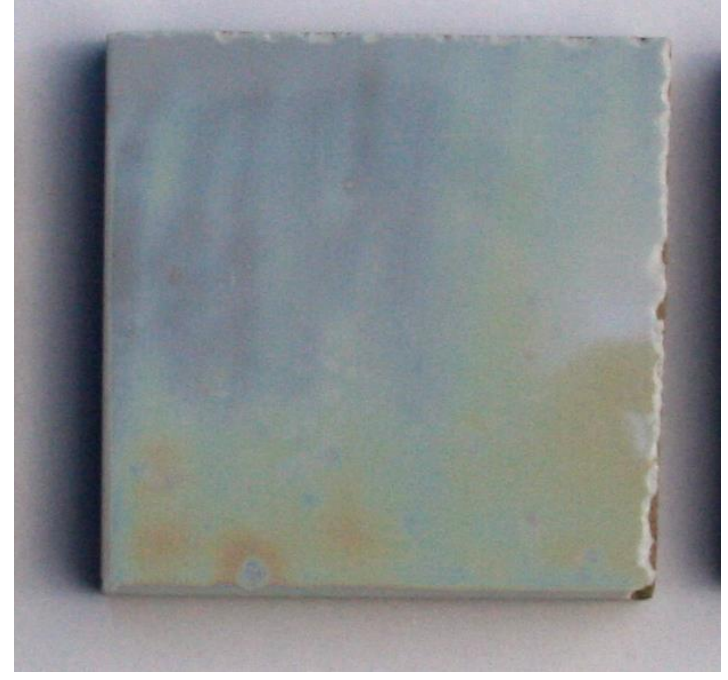

(a)

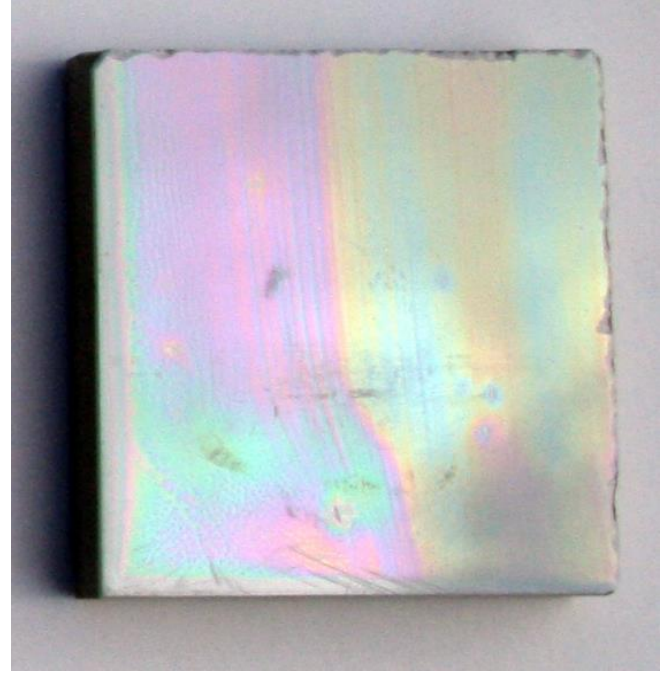

(b)

Figure 6. Porcelain stoneware samples with zirconium oxide enamel $\left(\mathrm{ZrO}_{2}\right)$ and final enamelling with anatase $\left(\mathrm{TiO}_{2}\right)$. Auditorium of Algueña (Casa de la Música y Auditorio de la Algueña, or MUCA).

(a) Sample of the second firing stage; (b) Sample of the fourth firing stage.

\section{Results}

\subsection{Physico-Chemical Analysis of the Ceramic Tiles}

The outer and inner enamels of the FEUA ceramic pieces, as well as a section or profile of the FEUA, were analysed in order to determine the various enamel layers applied. The results of the SEM analysis of the outer enamel, combined with its energy-dispersive X-ray spectrometry EDX, determined the presence of $\mathrm{Al}, \mathrm{Zn}$, and $\mathrm{Zr}$ (Table 1), in average proportions of $5.42 \%, 1.87 \%$, and $1.43 \%$, respectively.

Table 1. Average values of C norm. (wt.\%) for the outer enamel of the ceramic tiles. FEUA.

\begin{tabular}{|c|c|c|c|c|c|c|c|c|c|c|c|c|}
\hline \multicolumn{13}{|c|}{ C Norm. (wt.\%) Outer Enamel } \\
\hline Element & $\mathrm{C}$ & $\mathbf{O}$ & $\mathrm{Na}$ & Al & Si & $\mathbf{K}$ & $\mathrm{Ca}$ & $\mathrm{Fe}$ & $\mathrm{Zn}$ & $\mathrm{Zr}$ & $\mathrm{Pb}$ & - \\
\hline Average \% & 4.77 & 52.35 & 2.71 & 5.42 & 25.32 & 3.12 & 1.91 & 0.18 & 1.87 & 1.43 & 0.92 & $100 \%$ \\
\hline
\end{tabular}

Microscopy images at 350 magnifications show that the distribution of the $\mathrm{Al}$ and $\mathrm{Zn}$ atoms was homogeneous throughout the surface, while the $\mathrm{Zr}$ was concentrated at various isolated points in a quasi-circular shape measuring approximately $75 \mathrm{~mm}$ in diameter (Figures 7 and 8). This phenomenon resembles the results obtained for the MUCA, with similar metals ( $\mathrm{Al}, \mathrm{Zn}$, and $\mathrm{Zr}$ ), in which the $\mathrm{Zr}$ was also concentrated in isolated points, although with a smaller surface area (about $15 \mathrm{~m}$ in diameter), and with amorphous shapes other than circles [8]. The proportions of $\mathrm{Zn}$ and $\mathrm{Zr}$ were twice as high as in the case studied here. This point concentration causes a diffraction of light, which, depending on the incidence of sunlight and observation point, produces iridescent effects. In the case of a surface area that is 25 times larger, the ratio between the magnitude and the light wavelengths is different, producing much weaker iridescent effects, and significantly increasing the enamel's level of gloss. Figure 9 shows the X-ray spectrometry EDX of the outer enamel. 


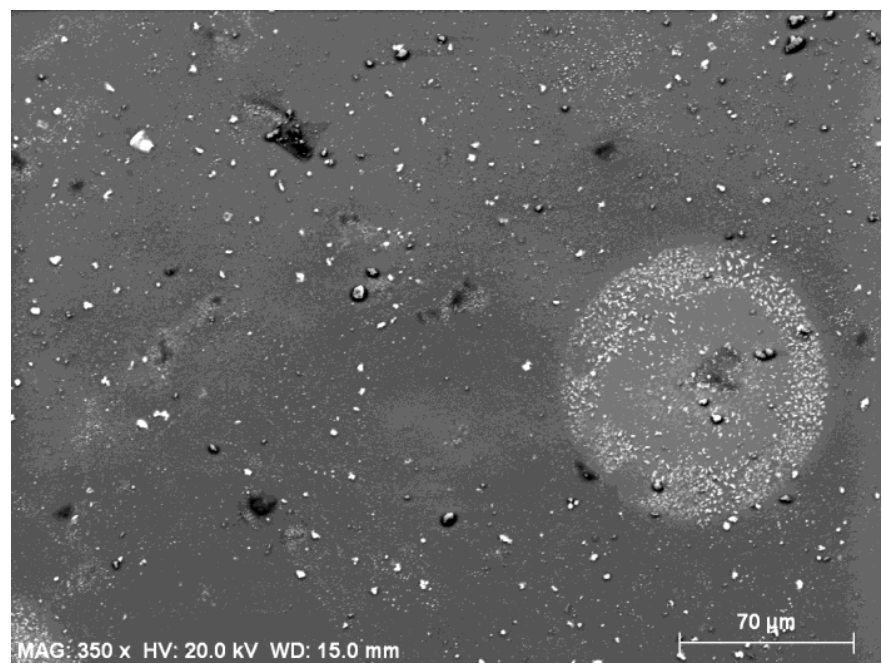

Figure 7. Microscopy of stoneware tiles with zirconium oxide $\left(\mathrm{ZrO}_{2}\right)$ enamel. FEUA.

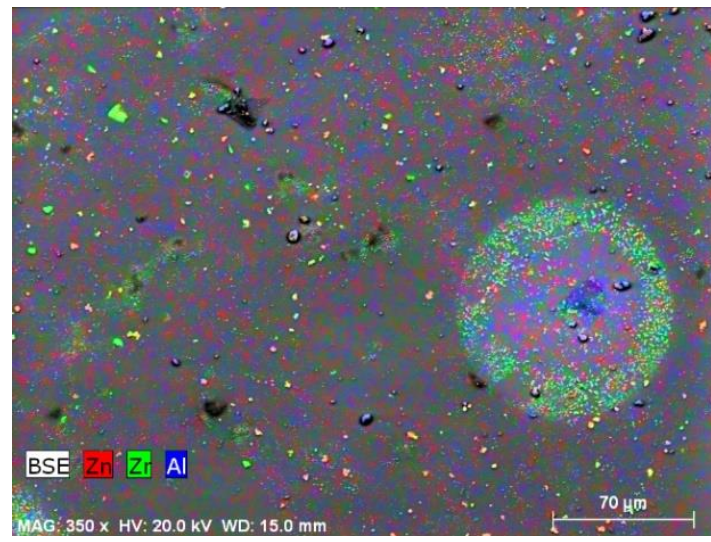

(a)

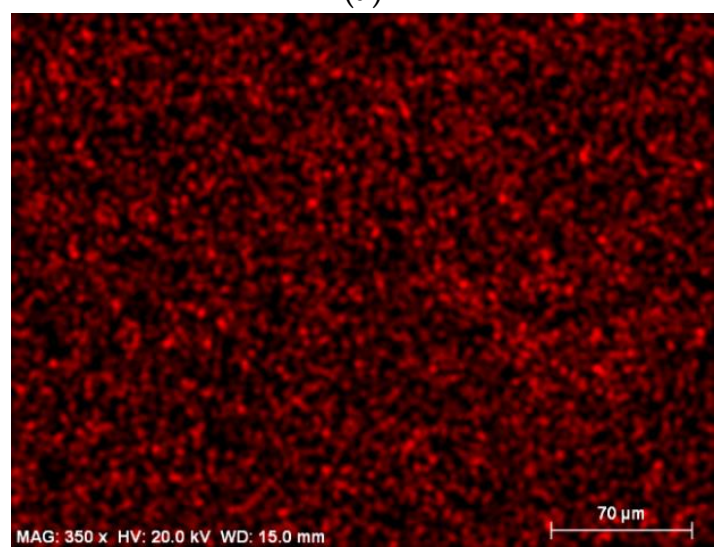

(c)

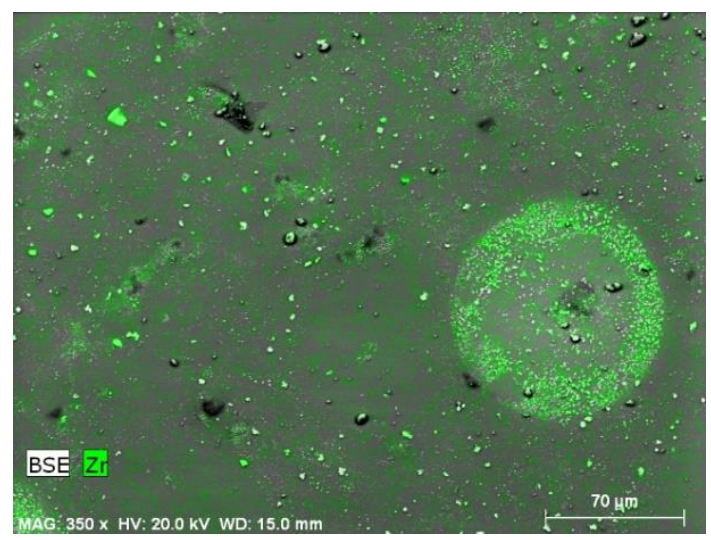

(b)

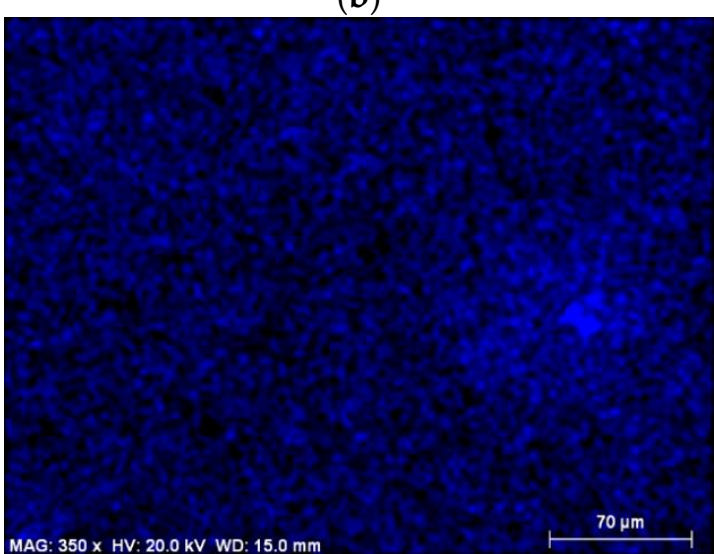

(d)

Figure 8. Microscopy of the stoneware tiles, FEUA. Outer enamel. (a) Zirconium, zinc and aluminium distribution; (b) zirconium unhomogeneous distribution; (c) zinc homogeneous distribution; (d) aluminium homogeneous distribution. 


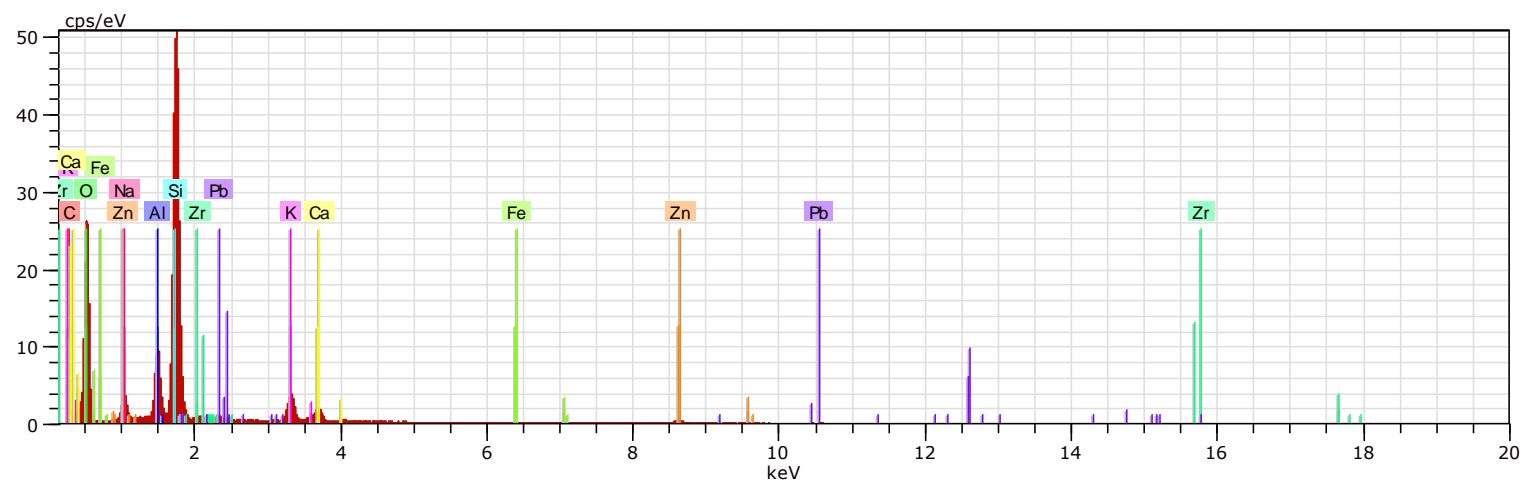

Figure 9. Energy-dispersive X-ray spectrometry (EDX). Outer enamel, sample 1. FEUA.

The XRD performed on the sample of ceramic outer enamel indicated the presence of $\mathrm{ZrSiO}_{4}$ zirconium silicate, coinciding with the SEM analysis (Figure 10). These results are similar to those obtained for the ceramic pieces of the Auditorium of the Algueña (MUCA). This zirconium dispersion produces the phenomenon of light diffraction by influencing zirconium and zinc. The physical-optical phenomenon is mainly caused by the lack of homogeneity in the distribution of $\mathrm{Zr}$, in the outer enamel layer. Light, in its path, encounters different refractive indexes between the $\mathrm{Zr}$ and $\mathrm{Zn}$ metals, diffracts in the crystallisation of zirconium silicate and also due to the its wavelength ratio to the dispersion of $\mathrm{Zr}$ [53]; it also induces the white light to separate into all the colours of the spectrum. The wavelengths produced interfere with each other causing iridescent effects.

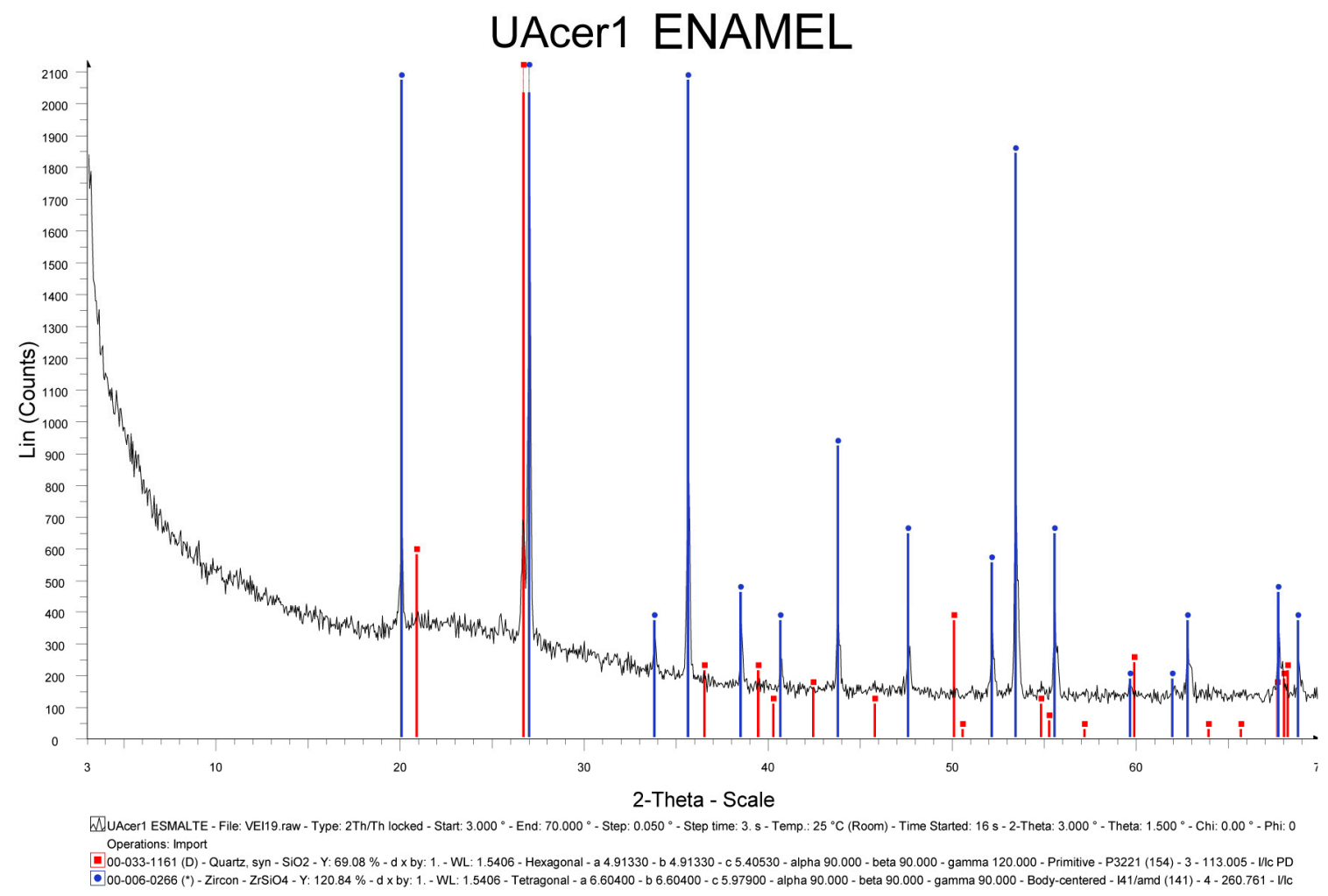

Figure 10. XRD of the outer enamel of the stoneware parts. FEUA.

To analyse the final reason explaining differences in iridescence between the two buildings, the various layers of enamel of both ceramic tiles were examined. To do this, a section or profile of the FEUA ceramic tile was analysed. As seen through microscopy images (Figure 11), and EDX analysis of the profile, only one enamel application was performed, with a single firing. Presence of silica-based 
slip was also observed. The same was observed again in the surface sample of dispersion of zirconium silicate $\mathrm{ZrSiO}_{4}$. Zn and Al display a homogeneous distribution (Figure 11). The EDX makes it possible to quantify the presence of metals, including $\mathrm{Zr}, \mathrm{Zn}$, and Al. The proportions are shown later in Table 2.

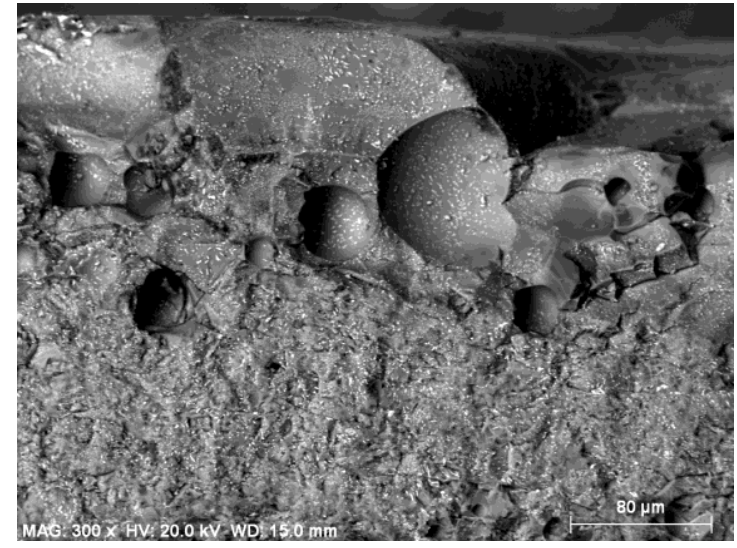

(a)

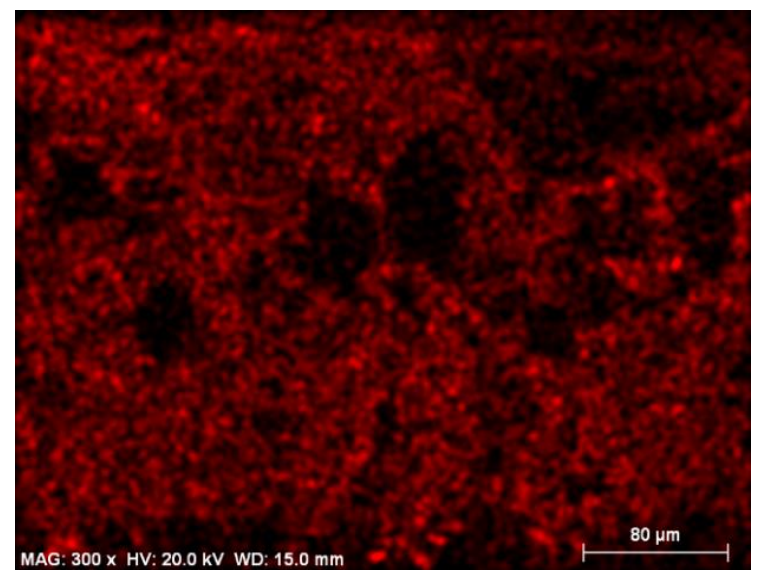

(c)

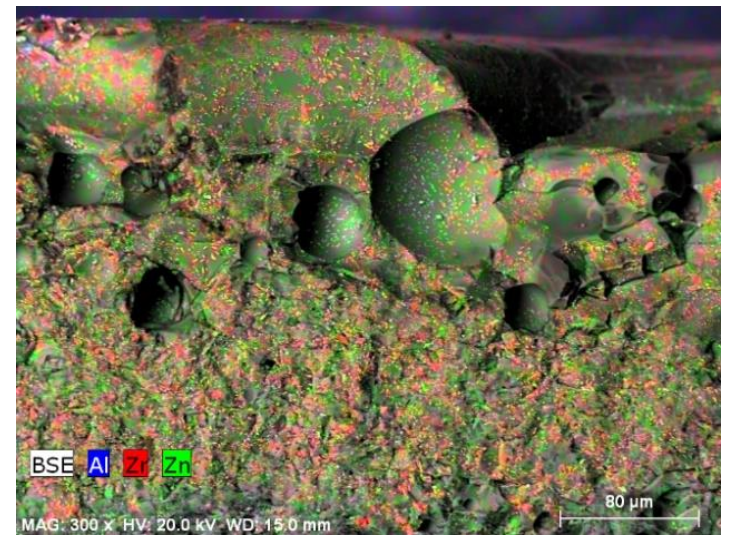

(b)

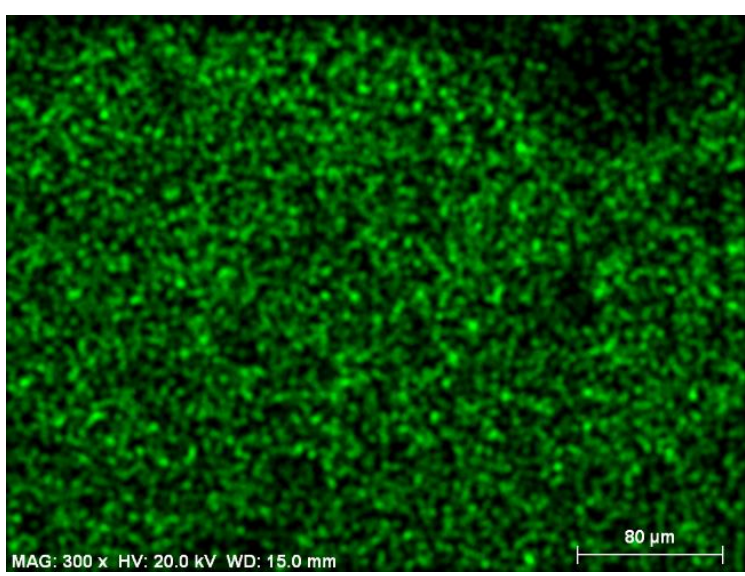

(d)

Figure 11. Scanning electron microscopy (SEM). Profile or section. Biscuit, slip and final enamel of the ceramic tile magnified 300 times. FEUA. (a) SEM image; (b) aluminium, zirconium and zinc distribution; (c) zirconium unhomogeneous distribution; (d) zinc homogeneous distribution.

In the case of the MUCA, three enamel layers were applied in the process, with three successive firings. As demonstrated in previous research, the final layer of $\mathrm{TiO}_{2}$ or anatase titanium oxide enamel, following the firing process at $750-780^{\circ} \mathrm{C}$, undergoes microcracking in the cooling phase (Figure 12) [8]. Magnifying 3000 times, a cracking of this last layer of anatase is observed, with a groove thickness between 0.5 and 1 micron. This micro-breathing is due to the differences in coefficients of thermal expansion between titanium and zirconium, 1.3 and $0.3 \times 10^{-5} \mathrm{in} / \mathrm{in} /{ }^{\circ} \mathrm{C}$. The anatase, in its final application, greatly reinforces the effect of light reflection iridescence both for its physical qualities and for its microcrack effect in relation to the wavelengths of light and its refraction [54]. The end result of the manufacturing process is porcelain stoneware tiles of well-known construction characteristics, but which incorporate a vitrified enamel without microcracks, making the ceramic pieces resistant to moisture, frost and chemical action, while enhancing the goniochromatic or iridescent colour properties. 
Table 2. Average values of C norm. (wt.\%) and presence of metals for all samples analysed.

\begin{tabular}{cccccc}
\hline \multicolumn{5}{c}{ Average Values of C Norm. (wt.\%) } \\
\hline Element & $\begin{array}{c}\text { Sample } \\
\text { Enamel 1 }\end{array}$ & $\begin{array}{c}\text { Sample } \\
\text { Enamel 2 }\end{array}$ & $\begin{array}{c}\text { Sample } \\
\text { Interior 1 }\end{array}$ & $\begin{array}{c}\text { Sample } \\
\text { Interior 2 }\end{array}$ & $\begin{array}{c}\text { Sample } \\
\text { Interior Profile }\end{array}$ \\
\hline $\mathrm{C}$ & 4.93 & 4.16 & - & - & 13.28 \\
$\mathrm{O}$ & 52.00 & 52.65 & 50.14 & 51.13 & 45.52 \\
$\mathrm{Na}$ & 2.51 & 2.72 & 0.67 & - & 1.33 \\
$\mathrm{Al}$ & 5.29 & 5.53 & 9.93 & 11.25 & 6.08 \\
$\mathrm{Si}$ & 25.32 & 25.32 & 19.17 & 18.11 & 18.02 \\
$\mathrm{~K}$ & 3.50 & 3.17 & - & 3.39 & 2.36 \\
$\mathrm{Ca}$ & 2.00 & 1.89 & 8.64 & 8.26 & 4.29 \\
$\mathrm{Fe}$ & 0.20 & - & 4.78 & 4.62 & 0.70 \\
$\mathrm{Zn}$ & 1.95 & 1.78 & - & - & 2.11 \\
$\mathrm{Zr}$ & 1.29 & 1.59 & - & - & 4.46 \\
$\mathrm{~Pb}$ & 1.02 & 0.97 & - & - & - \\
$\mathrm{Mg}$ & - & 0.22 & 2.01 & 1.68 & 0.37 \\
$\mathrm{~S}$ & - & - & 0.74 & 0.74 & - \\
$\mathrm{Cl}$ & - & - & 0.18 & - & - \\
$\mathrm{Ti}$ & - & - & 0.71 & 0.83 & - \\
$\mathrm{Ba}$ & - & - & - & - & - \\
$\mathrm{Ni}$ & - & - & - & - & 0.10 \\
$\mathrm{Mo}$ & - & - & - & - & 1.37 \\
$\mathrm{Total}$ & $100 \%$ & $100 \%$ & $100 \%$ & $100 \%$ & $100 \%$ \\
\hline
\end{tabular}

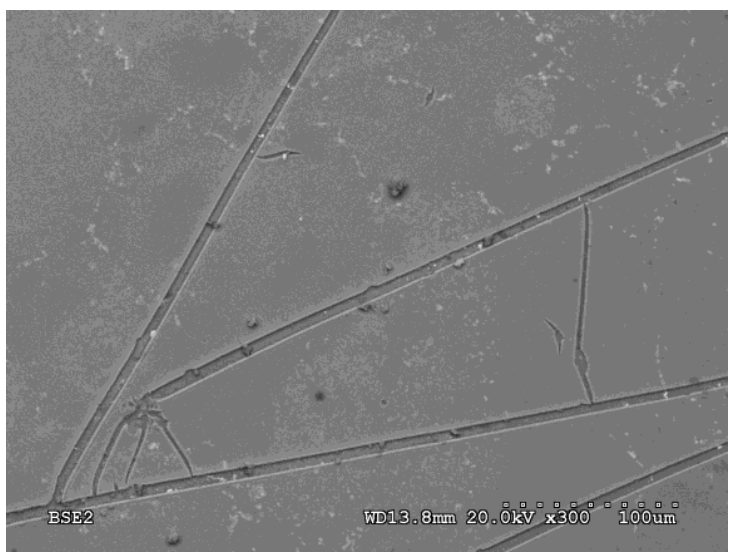

(a)

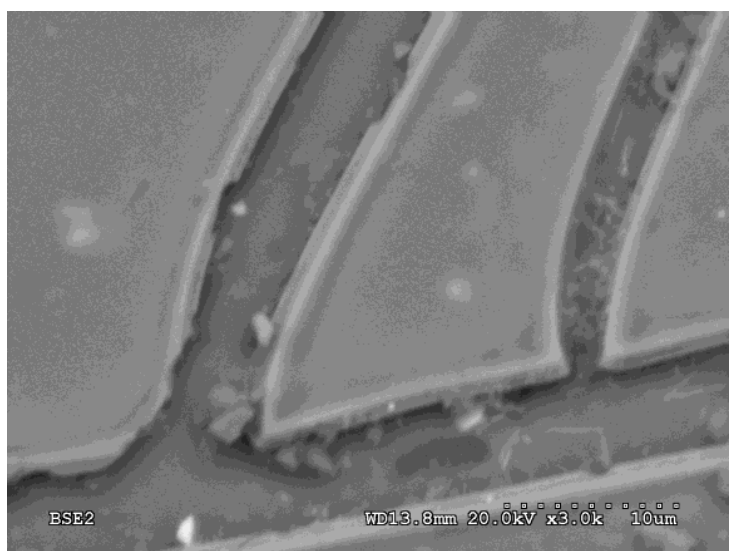

(b)

Figure 12. Ceramic pieces of the MUCA. Cracks in the final layer of anatase magnified 300 and 3000 times. (a) SEM image at 300 magnification; (b) SEM image at 3000 magnification.

We can conclude that the iridescent effect of the ceramic tiles of the FEUA is very weak due to, on the one hand, the lesser presence of zirconium silicate, which is about half that in the case of the MUCA, but above all, due to the absence of the final layer of anatase $\left(\mathrm{TiO}_{2}\right)$. The first tiles were made with a single-firing system versus the three firings of the second building. The targeted effect was to enhance the gloss against iridescence, as we will see in the colorimetric and gloss characterisation. The cost of the ceramic pieces is also much lower, which was one of the requirements of the FEUA project competition.

With regard to the inner face of the ceramic tile, without enamel (Figure 13), it is possible to review, through the XRD analysis, the presence of silica $\mathrm{SiO}_{2}$, Cristobalite $\mathrm{SiO}_{2}$, orthoclase $\mathrm{K}(\mathrm{Al}, \mathrm{Fe}) \mathrm{Si}_{2} \mathrm{O}_{8}$ - widely used as a flux material in the manufacturing of ceramics and porcelain - calcite magnesian (CM)- $\mathrm{Mg}_{0.1} \mathrm{Ca}_{0.9} \mathrm{CO}_{3}$, Dolomite $\mathrm{CaMg}\left(\mathrm{CO}_{3}\right)_{2}$ and rutile $\mathrm{TiO}_{2}$ (Figure 14). The presence of these elements and the metals $\mathrm{Al}, \mathrm{Fe}$ and $\mathrm{Ba}$ were also found via the EDX of SEM microscopy. The presence of barium Ba was also encountered, although the XRD analysis did not specify the 
presence of any compound including it. Figure 13 shows its dispersed distribution, marked in red and magnified 700 times under the microscope.

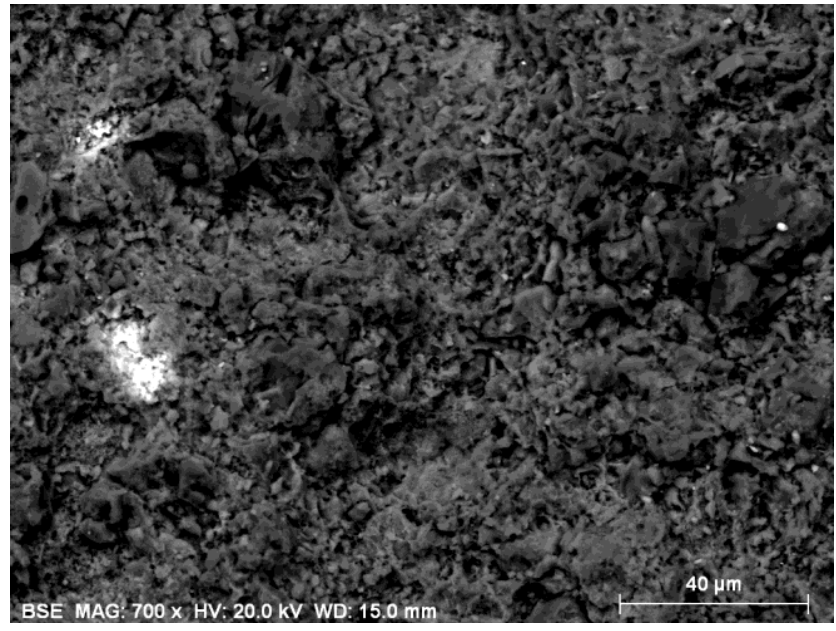

(a)

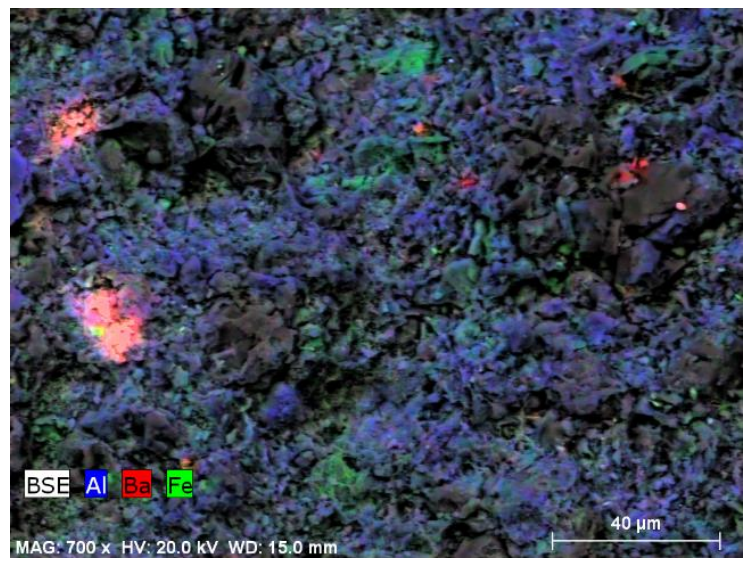

(b)

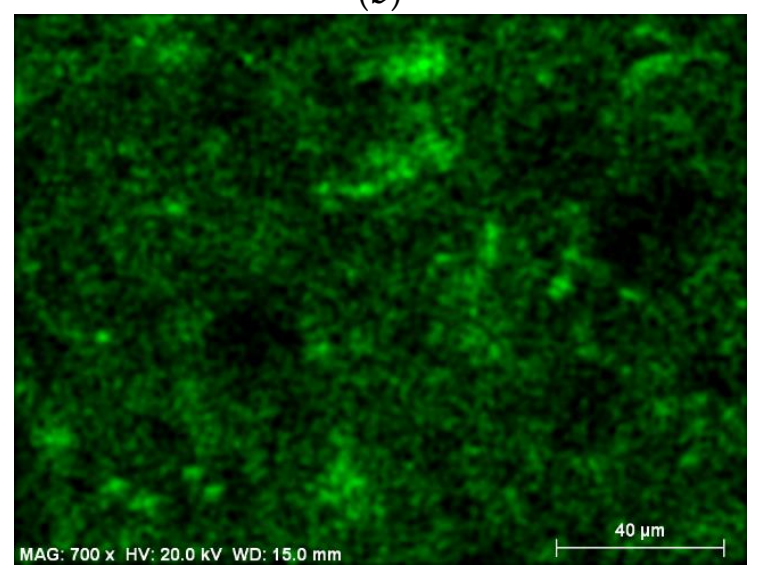

(d)

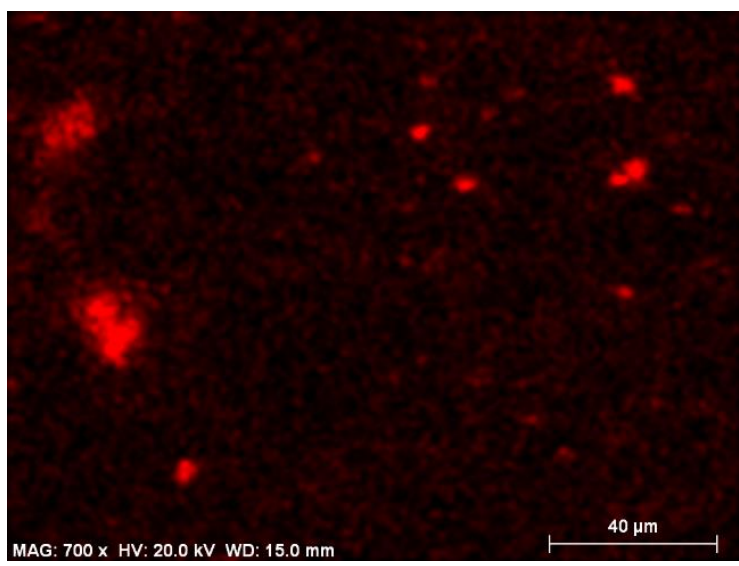

(c)

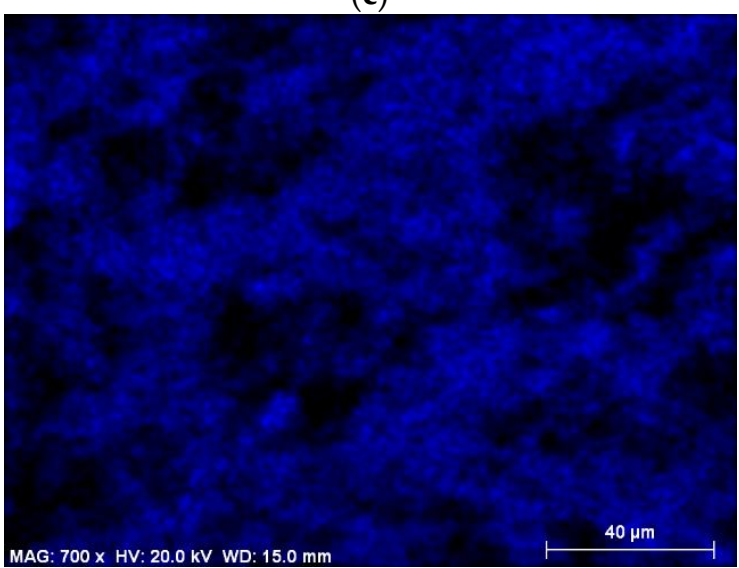

(e)

Figure 13. SEM of the inner face, unglazed. One can observe the presence of $\mathrm{Al}, \mathrm{Fe}$ and $\mathrm{Ba}$. FEUA. (a) SEM image; (b) aluminium, barium and iron distribution; (c) distribution of barium in points; (d) iron distribution; (e) aluminium distribution. 


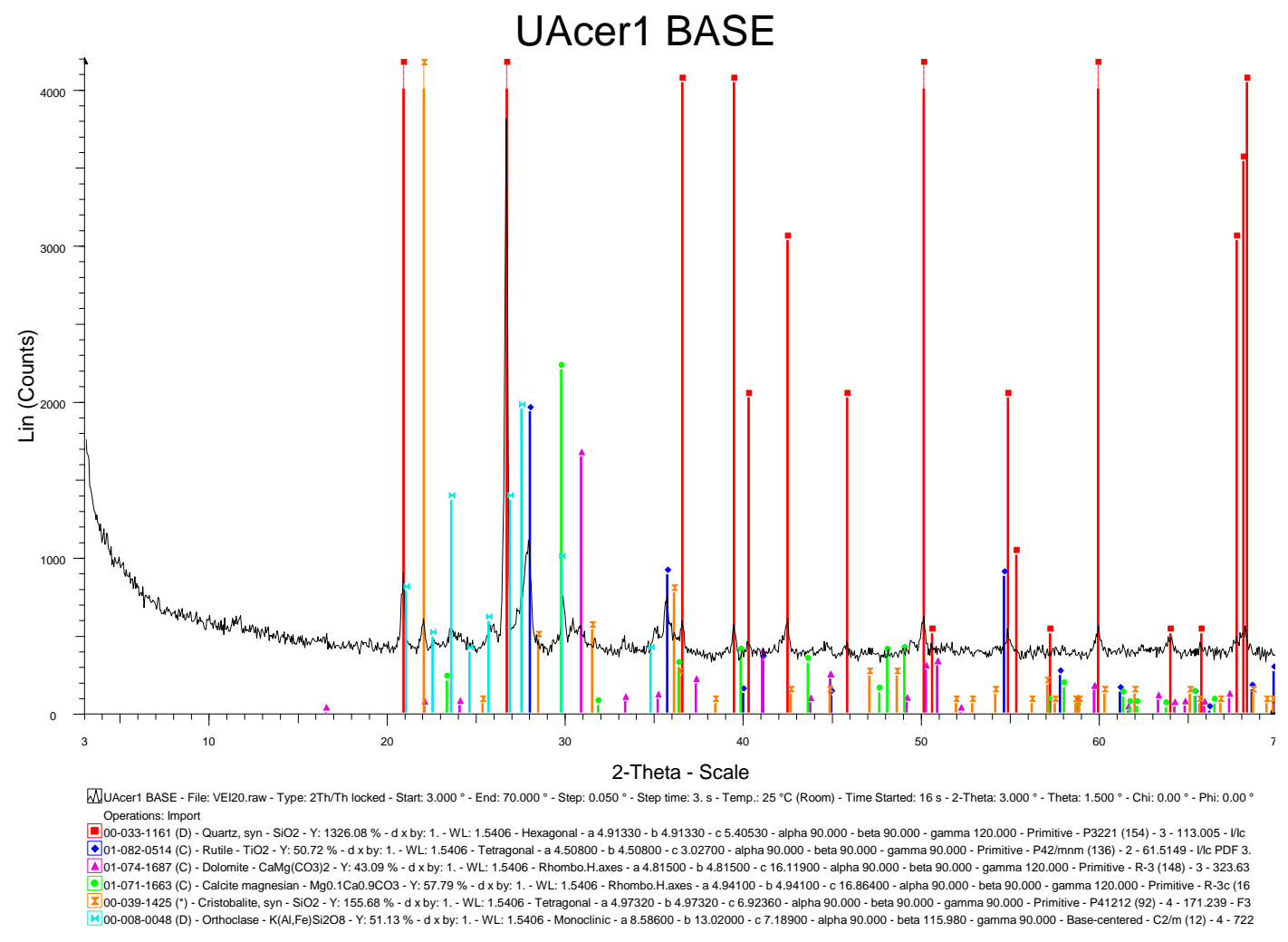

Figure 14. XRD of the inner, unglazed face. FEUA.

The presence of barium is due to the application of barium carbonate $\left(\mathrm{BaCO}_{3}\right)$, also known as witherite, which is added to clays to precipitate soluble salts (calcium and magnesium sulfate), which cause efflorescence in the stoneware. Barium oxide $\mathrm{BaO}$ is also frequently used in the application of enamels, acting as a flux, protection and crystallisation agent. It is combined with certain colouring oxides to produce unique colours not easily achievable by other means. This research has shown that it was not used in enamels applied in the FEUA.

The composition of the ceramic biscuit that serves to support the enamels differs substantially from the ceramic pieces of the Auditorium of the Algueña (MUCA), since in this case it is porcelain stoneware, made with other raw materials and with three firing materials, one of them at $1180^{\circ} \mathrm{C}$.

Table 2 shows the results of the element analysis or chemical characterisation of the energy-dispersive X-ray spectrometry (EDX) obtained for the outer face, the inner face and the profile or section of the ceramic sample analysed. Results of two measurements performed in two different areas of SEM microscopy are shown for both the outer face or enamel, and inside the ceramic tile. Only the "norm" value is displayed. $\mathrm{C}(\mathrm{wt} . \%)$, which is the normalised concentration in weight percent of each element. The presence of $\mathrm{Zr}$, $\mathrm{Zn}, \mathrm{Fe}$, and $\mathrm{Pb}$ in the enamel is observed, and the absence of $\mathrm{Ti}$, which only appears on the inner face or biscuit, although the Fe does not appear in the second measurement of the enamel. The presence of $\mathrm{Al}$ aluminium is notable in all parts of the analysed tile.

\subsection{Colorimetric and Gloss Analysis}

The colorimetric analysis of the ceramic tiles of the Faculty of Education of the University of Alicante (FEUA), measured with the multi-angle spectrophotometer BYK-mac i $23 \mathrm{~mm}$ (D65 illuminant), results in a high level of grey-colour homogeneity. Figure 15 shows the reflectance spectra curves for the characteristic grey colour, in which the colour curves according to observational geometries are very close (slight variation in luminosity) and share a similar form of spectrum (no shade variation). Unlike the MUCA ceramic pieces, they present a low degree of individual goniochromatism, allowing 
us to conclude that there is a very slight iridescence effect. Table 3 and Figure 16 show that the colour variation by observation geometries is very reduced, according to CIE $L^{*} a^{*} b^{*}$ units.

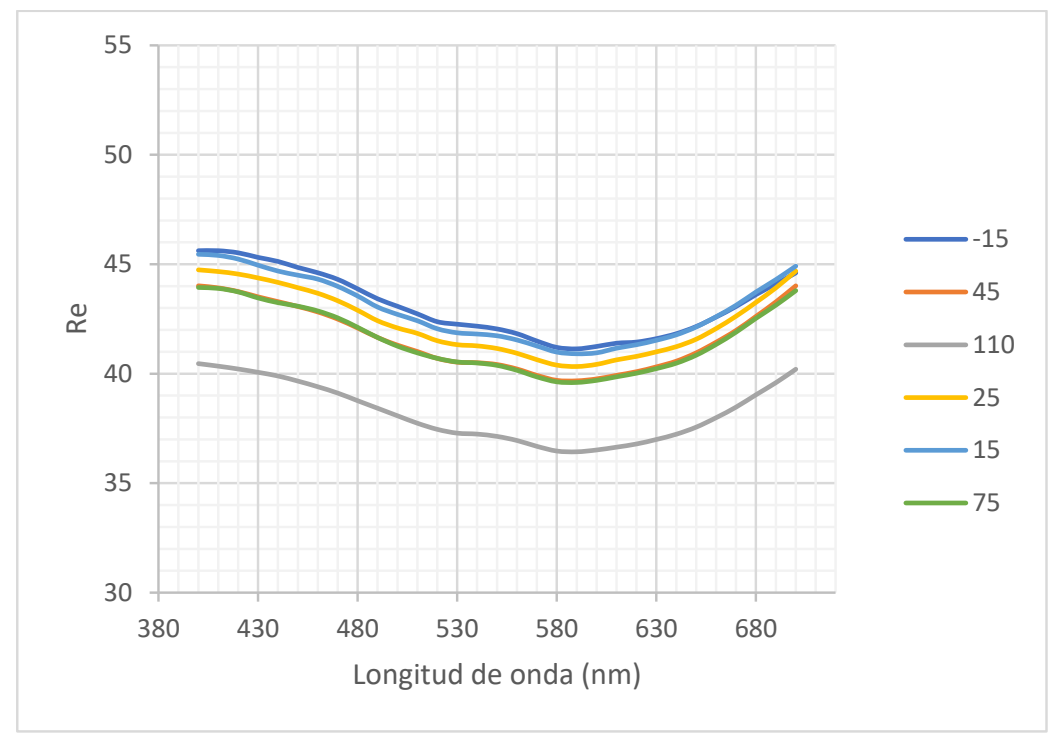

Figure 15. Spectral reflectance curves of the characteristic colours of FEUA ceramic tiles for the 6 geometries 45 as 110 to 45 as 15 .

Table 3. Values of CIE $L^{*}{ }^{*} b^{*}$ units for the 6 geometries 45 as 15 to 45 as 110 Ceramic tiles from the FEUA.

\begin{tabular}{ccccccc}
\hline \multicolumn{7}{c}{ Param2 STD: Sample FEUA } \\
\hline Angle & $\boldsymbol{L}^{*}$ & $\boldsymbol{a}^{*}$ & $\boldsymbol{b}^{*}$ & $\boldsymbol{C}^{*}$ & $\boldsymbol{h}^{\circ}$ & Angle \\
\hline-15 & 70.97 & 0.22 & -3.00 & 3.00 & 274.25 & -15 \\
15 & 70.77 & 0.36 & -2.95 & 2.97 & 276.87 & 15 \\
25 & 70.37 & 0.38 & -2.93 & 2.96 & 277.31 & 25 \\
45 & 69.85 & 0.43 & -2.85 & 2.89 & 278.67 & 45 \\
75 & 69.82 & 0.40 & -2.90 & 2.93 & 277.79 & 75 \\
110 & 67.47 & 0.35 & -2.85 & 2.87 & 277.07 & 110 \\
\hline
\end{tabular}

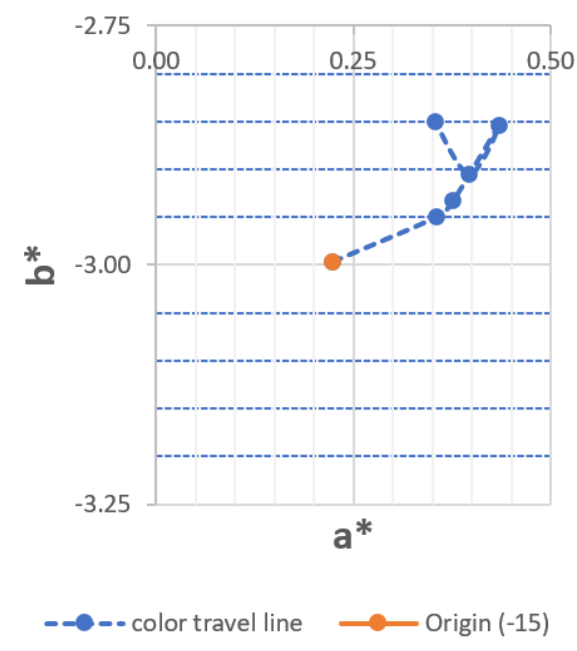

(a)

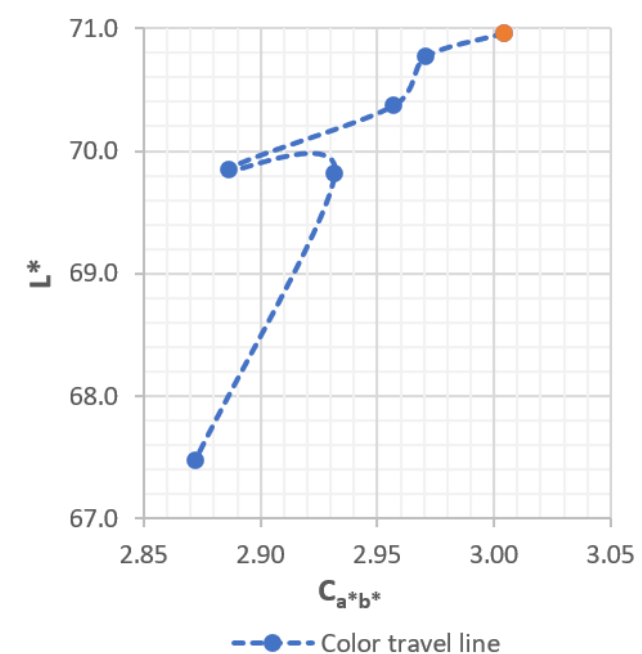

(b)

Figure 16. CIE Lightness $\left(L^{*}\right)$, tone profiles $\left(a^{*}, b^{*}\right)$ and Chroma/Clarity $\left(C_{a^{*}, b^{*}}\right)$ for the six measurements geometries. (a) CIE $L^{*}{ }^{*} b^{*}$ plane plot (Hue representation); (b) CIE $C^{*} \cdot L_{a^{*} b^{*}}$ plane plot (Chroma versus Lightness representation). FEUA. 
In the MUCA, by means of the group analysis of the characteristic colours, and grouping the reflectance measurements according to the six geometries in each characteristic colour, it was possible to verify that following the thermal curing process, these colours presented a certain degree of individual goniochromatism (Figure 17), but it was not so high compared to the goniochromatic colours $[30,39]$ currently used in automotive paints [40], cosmetics, etc.

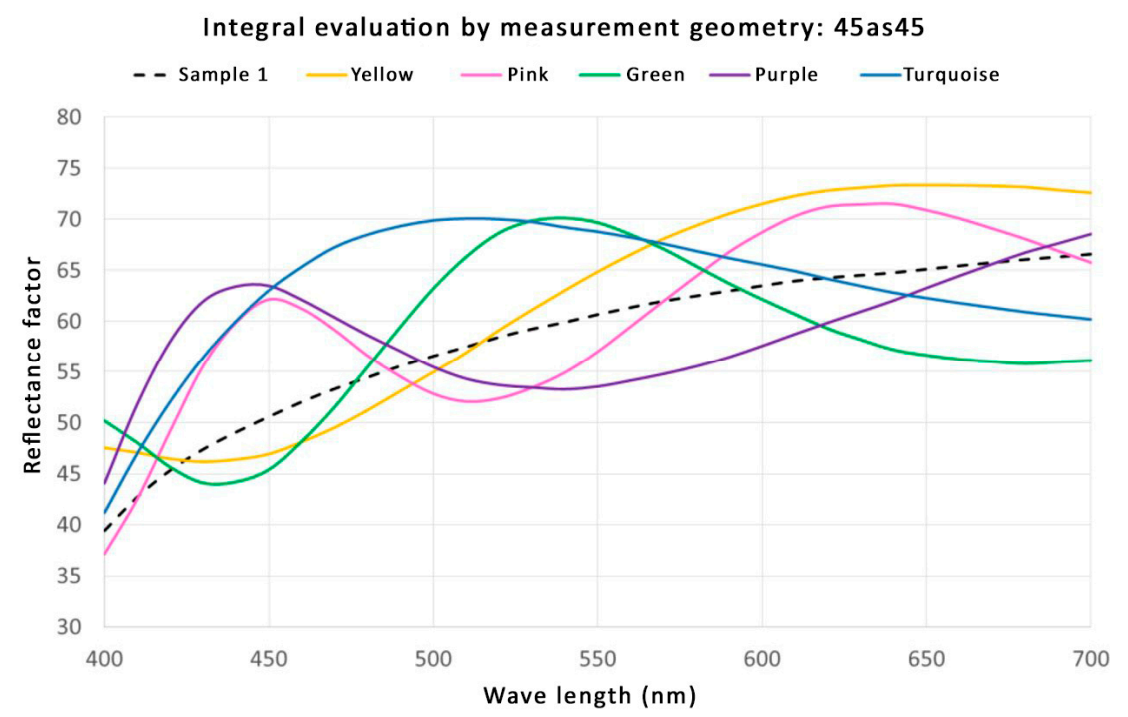

Figure 17. Spectral reflectance curves of the characteristic colours of MUCA ceramic tiles for the 6 geometries 45 as 110 to 45 as 15 .

With regard to gloss measurements, as set out in the methodology, the glossmeter was applied to the ceramic tiles of the FEUA and the MUCA (Figure 18). Tables 4 and 5 show sample gloss measurements in GU (Gloss Units), based on the 20-degree light angle. They were measured up to 10 times at the same point to check measurement repeatability and to validate the results, which were satisfactory. They were then measured at three different points to observe the levels of gloss homogeneity throughout the material. Although the results are displayed according to the $20^{\circ}$ light angle, measurements were made, as required, at $20^{\circ}, 60^{\circ}$, and $85^{\circ}$. Since values at $60^{\circ}$ exceeded the value " $70^{\prime \prime}$, the measurement value selected was $20^{\circ}$.

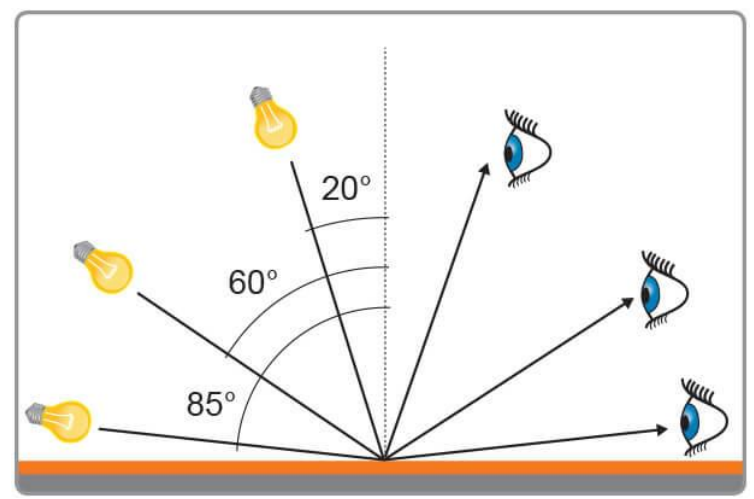

(a)

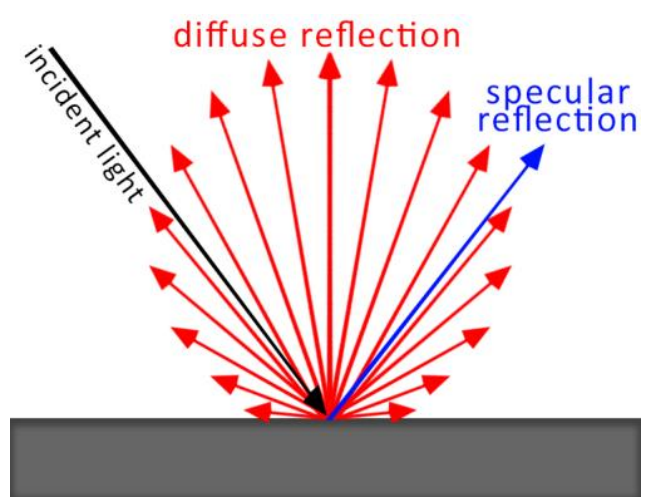

(b)

Figure 18. Gloss measurement scheme with Minolta Multi-Gloss 268, for $20^{\circ}, 60^{\circ}$, and $85^{\circ}$ angles. (a) Incident light angles; (b) light detector positions. 
Table 4. Results of 10 gloss measurements of one point in the FEUA tiles.

\begin{tabular}{|c|c|c|c|}
\hline \multirow{2}{*}{ Measure } & \multicolumn{3}{|c|}{ Angle (Deg) } \\
\hline & $20^{\circ}$ & $60^{\circ}$ & $85^{\circ}$ \\
\hline Number & \multicolumn{3}{|c|}{ GU (Gloss Units) } \\
\hline 1 & 67.30 & 80.30 & 84.60 \\
\hline 2 & 67.40 & 80.20 & 84.70 \\
\hline 3 & 67.30 & 80.20 & 84.80 \\
\hline 4 & 67.40 & 80.20 & 84.70 \\
\hline 5 & 67.60 & 80.10 & 85.20 \\
\hline 6 & 67.90 & 80.30 & 85.70 \\
\hline 7 & 68.00 & 80.20 & 85.20 \\
\hline 8 & 68.20 & 80.30 & 84.90 \\
\hline 9 & 67.70 & 80.10 & 84.60 \\
\hline 10 & 68.20 & 80.50 & 84.80 \\
\hline Average & 67.6 & 80.2 & 84.9 \\
\hline Standard deviation & 0.4 & 0.1 & 0.3 \\
\hline
\end{tabular}

Table 5. Gloss measurement results for three points of FEUA tiles.

\begin{tabular}{|c|c|c|c|}
\hline \multirow{3}{*}{ Measure } & \multicolumn{3}{|c|}{ Angle (Deg) } \\
\hline & $20^{\circ}$ & $60^{\circ}$ & $85^{\circ}$ \\
\hline & \multicolumn{3}{|c|}{ GU (Gloss Units) } \\
\hline Point 1 & - & - & - \\
\hline Average & 62.1 & 81.1 & 82.3 \\
\hline Standard deviation & 0.0 & 0.1 & 1.0 \\
\hline Point 2 & - & - & - \\
\hline Average & 68.8 & 81.4 & 84.1 \\
\hline Standard deviation & 0.1 & 0.1 & 0.1 \\
\hline Point 3 & - & - & - \\
\hline Average & 62.5 & 81.0 & 81.9 \\
\hline Standard deviation & 0.7 & 0.0 & 0.1 \\
\hline Media Global & 64.5 & 81.2 & 82.7 \\
\hline Standard deviation & 3.2 & 0.2 & 1.2 \\
\hline
\end{tabular}

The value, at $20^{\circ}, 60^{\circ}$, and $85^{\circ}$, is high. The comparison with the MUCA ceramic pieces produced significant results. At $20^{\circ}$ and $60^{\circ}$ angles, the gloss is null, and the appearance is matte. This may be due to the presence of microcracks in the last anatase layer, which prevents light reflection at low incidence angles [55]. When the angle increases to $85^{\circ}$, the gloss values are very high, around 97.2 (Table 6). This value exceeds that of the ceramic tiles of the FEUA. We can conclude that when an observer is roughly facing the front of the FEUA building, the gloss value is high; the façade reflects its surroundings relatively faithfully as far as colours are concerned, whereas in the case of the MUCA, it is mainly iridescence that reaches the observer's eye, and colours in the surroundings are only reflected at high observation angles.

The characteristic colours of the FEUA environment—reddish, greenish and blue-are reflected on the uneven surface of the ceramic tiles. Due to the enamel's high gloss index and dark grey base, notable light vibrations are produced for observers. When an observer crosses the campus, a visual phenomenon resembling iridescence occurs, although it differs from iridescence regarding its ultimate causes. The $\mathrm{ZrSiO}_{4}$ zirconium silicate present in the enamel layer [56], coupled with its surface irregularities, increases the reflection of sunlight [57] and produces light diffraction values, with an aesthetically attractive result. The phenomenon is intensified at night, under artificial halide-lamp lighting. 
Table 6. Three-point gloss measurement results of the ceramic pieces of the MUCA.

\begin{tabular}{cccc}
\hline & \multicolumn{3}{c}{ Angle (Deg) } \\
\cline { 2 - 4 } Measure & $\mathbf{2 0 ^ { \circ }}$ & $\mathbf{6 0}^{\circ}$ & $\mathbf{8 5 ^ { \circ }}$ \\
\cline { 2 - 4 } & GU (Gloss & Units) \\
\hline Point 1 & - & - & - \\
Average & 0.0 & 0.0 & 97.2 \\
Standard deviation & 0.0 & 0.0 & 0.1 \\
Point 2 & - & - & - \\
Average & 0.0 & 0.0 & 97.1 \\
Standard deviation & 0.0 & 0.0 & 0.1 \\
Point 3 & - & - & - \\
Average & 0.0 & 0.0 & 97.4 \\
Standard deviation & 0.0 & 0.0 & 0.2 \\
Media Global & 0.0 & 0.0 & 97.2 \\
Standard deviation & 0.0 & 0.0 & 0.2 \\
\hline
\end{tabular}

\section{Conclusions}

When applied to building façade claddings, ceramic tile enamels based on metal deposition of $\mathrm{ZrO}_{2}$ zirconium oxide combined with additional techniques can trigger singular reflection and light refraction effects for observers. Sometimes one encounters marked iridescence and on other occasions this effect is combined with the reflection of the range of colours in the surroundings due to high levels of gloss.

In the present study, we examined the application of these enamels to intense grey-based tiles manufactured by extrusion. The irregularities of the surface, contrary to that of a press manufacturing system, together with the semi-craftsmanship application of enamel, cause the FEUA's pieces to generate an iridescent-like visual effect for observers. But the colorimetric characterisation analysis, compared to the ceramic pieces of the MUCA, with a marked iridescent effect and an attractive range of goniochromatic colours, has shown that the iridescent effect is very weak. The characteristic colours of the FEUA's surroundings-reddish, greenish and blue-are reflected by the uneven surface of the ceramic tiles. Due to the high gloss index and dark-grey base of its enamel, significant light vibrations are produced for observers, as well as a varied range of colours. When circulating through the campus, a visual phenomenon occurs resembling that of iridescence, although for different reasons.

Despite the presence of zirconium silicate $\left(\mathrm{ZrSiO}_{4}\right)$ in the applied enamel, which is distributed non-homogeneously on the surface, and of other metals such as $\mathrm{Zn}$ and $\mathrm{Al}$, similar to those observed in the ceramic pieces of the MUCA in a physical-chemical analysis by microscopy, the ceramic tiles of the FEUA do not contain a finishing layer based on anatase $\mathrm{TiO}_{2}$. This layer, present in the MUCA, underwent microcracking based on the two underlying $\mathrm{ZrO}_{2}$ and $\mathrm{ZnO}$ based enamels applied with a brush. The microcracks are responsible for multiplying iridescent effects, producing a marked and varied diffraction of light across the surface of the pieces.

The gloss measurement values of both tiles were very different. In the case of the FEUA, the values at $20^{\circ}$ produced on average 64.5 gloss units, while at $60^{\circ}$ and $85^{\circ}$, they produced values of 81.2 and 82.7 , respectively. In the case of the MUCA, there were no gloss values at $20^{\circ}$ and $60^{\circ}$. The behaviour was thus almost matte, while at $85^{\circ}$, the value was very high: 97.2 gloss units.

The characteristic colours of the FEUA ceramic tiles, given their spectral and colorimetric characterisation for various representative measurement geometries, can provide a much broader range of colours, which could be observed in this building under artificial lighting in specific positions and directions.

Author Contributions: Conceptualization, methodology, SEM microscopy and XRD of the ceramic samples, funding acquisition, V.E.-I.; investigation, writing-original draft preparation, V.E.-I. and C.R.-M.; analysis of color and gloss characterization results, C.R.-M. and V.E.-I. All authors have read and agreed to the published version of the manuscript. 
Funding: This research has been funded by the project "Generation of knowledge on the multisensory interaction of the human being with the environments for the development of new products and services in the ceramic sector (4 SENSES)", reference PSE-020400-2007-1, of the Ministry of Science and Innovation (Spain), of the Single Strategic Plan (2007-2009).

Acknowledgments: Our thanks to Antonio Morata, Director of the Technical Office of the University of Alicante, and Francisco Miguel Martínez Verdú and Valentín Viqueira Pérez, of the Vision and Colour Group of the University of Alicante. http://web.ua.es/gvc. University Institute of Applied Physics to Science and Technologies (IUFACyT).

Conflicts of Interest: The funders had no role in the design of the study; in the collection, analyses, or interpretation of data; in the writing of the manuscript, or in the decision to publish the results.

\section{References}

1. Echarri Iribarren, V. Ceramics and energy efficiency: Passive and active conditioning systems. In Rhythms, Cycles, Performances-Ceramics in Architecture; Salazar, J., Sakamoto, T., Eds.; ASCER. ACTAR Publishers: Barcelona, Spain, 2010; pp. 92-95.

2. Silva Moreno, G.; Mira Peidró, J. Innovative products in the ceramic sector. In Public Private Ephemeral: Ceramics in Architecture; Delbene, G., Ed.; ASCER. ACTAR Publishers: Barcelona, Spain, 2008; pp. 46-50.

3. Ceramic Floor and Wall Tiles. Innovation, Avant-Garde and Sustainability in Public and Private Spaces. Report. Available online: http://www.promateriales.com/pdf/pm2209.pdf (accessed on 9 April 2019).

4. Ahmad, I.; Yazdani, B.; Zhu, Y. Recent advances on carbon nanotubes and graphene reinforced ceramics nanocomposites. Nanomaterials 2015, 5, 90-114. [CrossRef] [PubMed]

5. Chen, Z.; Guo, N.; Ji, L.; Xu, C. Synthesis of $\mathrm{CaF}_{2}$ nanoparticles coated by $\mathrm{SiO}_{2}$ for improved $\mathrm{Al}_{2} \mathrm{O}_{3} / \mathrm{TiC}$ self-lubricating ceramic composites. Nanomaterials 2019, 9, 1522. [CrossRef] [PubMed]

6. Giuranno, D.; Bruzda, G.; Polkowska, A.; Nowak, R.; Polkowski, W.; Kudyba, A.; Sobczak, N.; Mocellin, F.; Novakovic, R. Design of refractory $\mathrm{SiC} / \mathrm{ZrSi}_{2}$ composites: Wettability and spreading behavior of liquid Si-10Zr alloy in contact with SiC at high temperaturas. J. Eur. Ceram. Soc. 2020, 40, 953-960. [CrossRef]

7. Villalba Weinberg, A.; Goeuriot, D.; Poirier, J.; Varona, C.; Chaucherie, X. Mullite-zirconia composite for the bonding phase of refractory bricks in hazardous waste incineration rotary kiln. J. Eur. Ceram. Soc. 2020, 13492. [CrossRef]

8. Echarri Iribarren, V.; González Avilés, A.B.; Ródenas, M.; Olivares, J. Ceramics and reflected light new pearlescent and iridescent techniques and colorimetric characterization. Informes Constr. 2016, 68, e164. [CrossRef]

9. Xu, Q.; Ma, H.M.; Zhang, Y.J.; Li, R.S.; Sun, H.Y. Synthesis of iridiscent Ni-containing anodic aluminium oxide films by anodization in oxalic acid. Opt. Mater. 2016, 52, 107-110. [CrossRef]

10. Xu, Q.; Sun, C.X.; Wang, Z.J.; Liu, J.J.; Ren, Y.X.; Hao, S.Z.; Zhu, J.L.; Sun, Y.B.; Sun, H.Y. Preparation and characterization of iridescent $\mathrm{Ni}_{1-x} \mathrm{Co}_{x}$-containing anodic aluminum oxide films. Dyes Pigment. 2017, 147, 313-317. [CrossRef]

11. Wang, X.H.; Akahane, T.; Orisaka, H.; Kyotani, T. Brilliant and tunable color carbon-coated thin anodic aluminium oxide films. Appl. Phys. Lett. 2007, 91, 011908. [CrossRef]

12. Li, F.; Tang, B.; Zhang, S. Iridescent structural colors from self-assembled polymer opal of polythiourethane microspheres. Dyes Pigment. 2017, 142, 371-378. [CrossRef]

13. Song, L.; Chen, X.; Xie, Y.; Zhong, L.; Zhang, X.; Cheng, Z. Non-iridescent, crack-free, conductive structural colors enhanced by flexible nanosheets of reduced graphene oxide. Dyes Pigment. 2019, 164, 222-226. [CrossRef]

14. Liu, Y.; Hu, S.; Zhang, Y.; Wang, Z.; Zhou, G.; Wang, S. Crystal structure evolution and luminescence property of $\mathrm{Ce}^{3+}$-doped $\mathrm{Y}_{2} \mathrm{O}_{3}-\mathrm{Al}_{2} \mathrm{O}_{3}-\mathrm{Sc}_{2} \mathrm{O}_{3}$ ternary ceramics. J. Eur. Ceram. Soc. 2020, 40, 840-846. [CrossRef]

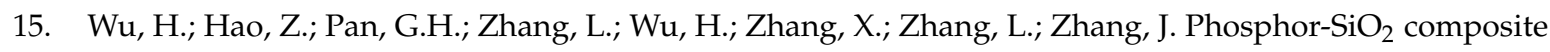
films suitable for white laser lighting with excellent color rendering. J. Eur. Ceram. Soc. 2020, 40, 2439-2444. [CrossRef]

16. Rojas-Hernandez, R.E.; Rubio-Marcos, F.; Serrano, A.; Salas, E.; Hussainova, I.; Fernandez, J.F. Towards blue long-lasting luminescence of Eu/Nd-doped calcium-aluminate nanostructured platelets via the molten salt route. Nanomaterials 2019, 9, 1473. [CrossRef] [PubMed]

17. Hřibalová, S.; Pabst, W. Light scattering and extinction in polydisperse systems. J. Eur. Ceram. Soc. 2020, 40, 867-880. [CrossRef] 
18. Qian, K.; Pan, Y.; Hu, Z.; Chen, X.; Shi, Y.; Liu, X.; Chen, H.; Nikl, M.; Li, J. Influence of co-doped alumina on the microstructure and radioluminescence of $\mathrm{SrHfO}_{3}$ :Ce ceramics. J. Eur. Ceram. Soc. 2020, 40, 449-455. [CrossRef]

19. Mirdali, N.K.; Daday, M.; Daday, M.T. Development and characterization of low temperature metallic glazes in $\mathrm{Na}_{2} \mathrm{O}-\mathrm{B}_{2} \mathrm{O}_{3}-\mathrm{SiO}_{2}$ (NBS) system. Ceram. Int. 2019, 45, 21661-21667. [CrossRef]

20. Pradell, T.; Pavlov, R.S.; Gutiérrez, P.C.; Climent-Font, A.; Molera, J. Composition, nanostructure, and optical properties of silver and silvercopper lusters. J. Appl. Phys. 2012, 112, 054307. [CrossRef]

21. Bobin, O.; Schvoerer, M.; Miane, J.L.; Fabre, J.F. Colored metallic shine associated to luster decoration of glazed ceramics: A theoretical analysis of the optical properties. J. Non Cryst. Solids 2003, 332, 28-34. [CrossRef]

22. Jiang, W.; Xu, X.; Chen, T.; Liu, J.; Zhang, X. Preparation and chromatic properties of $\mathrm{C} @ Z r S i O_{4}$ inclusion pigment via non-hydrolytic sol-gel method. Dyes Pigment. 2015, 114, 55-59. [CrossRef]

23. Badenes, J.A.; Llusar, M.; Tena, M.A.; Calbo, J.; Monrós, G. Praseodymium-doped cubic Ca- $\mathrm{ZrO}_{2}$ ceramic stain. J. Eur. Ceram. Soc. 2020, 22, 1981-1990. [CrossRef]

24. Yuan, L.; Han, A.; Ye, M.; Chen, X.; Ding, C.; Yao, L. Synthesis and characterization of novel non-toxic $\mathrm{BiFe}_{1-x} \mathrm{Al}_{x} \mathrm{O}_{3} /$ mica-titania pigments with high NIR reflectance. Ceram. Int. 2017, 43, 16488-16494. [CrossRef]

25. Kaya, S.Y.; Karasu, B. Process parameters determination of phosphorescent pigment added, frit-based wall tiles vetrosa decorations. Ceram. Int. 2012, 38, 2757-2766. [CrossRef]

26. Gao, Y.F.; Zhao, F.; Liu, Y.; Luo, H.J. Synthesis and characterization of $\mathrm{ZrO}_{2}$ capsules and crystalline $\mathrm{ZrO}_{2}$ thin layers on $\mathrm{Fe}_{2} \mathrm{O}_{3}$ powders. CrystEngComm 2011, 13, 3511-3514. [CrossRef]

27. Cavalcante, P.; Dondi, M.; Guarini, G.; Raimondo, M.; Baldi, G. Colour performance of ceramic nano-pigments. Dyes Pigm. 2009, 80, 226-232. [CrossRef]

28. Jovaní, M.; Domingo, M.; Machado, T.R.; Longo, E.; Beltrán-Mir, H.; Cordoncillo, E. Pigments based on $\mathrm{Cr}$ and $\mathrm{Sb}$ doped $\mathrm{TiO}_{2}$ prepared by microemulsionmediated solvothermal synthesis for inkjet printing on ceramics. Dyes Pigm. 2015, 116, 106-113. [CrossRef]

29. Fu, J.; Peng, Y.; Tian, X. Pigments Having Angle Dependence of the Interference Colours and Its Production Process. U.S. Patent US8066811B2, 29 November 2011.

30. Cabrera, M.J.; Montins, V.; Solsona, D.; Sala, J.M. Obtención de efectos físico-ópticos para la decoración de baldosas cerámicas. Boletín Sociedad Española Cerámica y Vidrio 2012, 51, IX-XVI. [CrossRef]

31. Tena, M.A.; Meseguer, S.; Gargori, C.; Forés, A.; Badenes, J.A.; Monrós, G. Study of $\mathrm{Cr}-\mathrm{SnO}_{2}$ ceramic pigment and of Ti/Sn ratio on formation and coloration of these materials. J. Eur. Ceram. Soc. 2007, 27, 215-221. [CrossRef]

32. Shen, Z.; Liu, L.; Xu, X.; Zhao, J.; Eriksson, M.; Zhong, Y.; Adolfsson, E.; Liu, Y.; Kocjan, A. Fractography of self-glazed zirconia with improved reliability. J. Eur. Ceram. Soc. 2017, 37, 4339-4345. [CrossRef]

33. Cannio, M.; Bondioli, F. Mechanical activation of raw materials in the synthesis of $\mathrm{Fe}_{2} \mathrm{O}_{3}-\mathrm{ZrSiO}_{4}$ inclusion pigment. J. Eur. Ceram. Soc. 2012, 32, 643-647. [CrossRef]

34. Hainschwang, T.; Notari, F. The cause of iridescence in rainbow andradite from Nara: Japan. Gems Gemol. 2006, 42, 248-258. [CrossRef]

35. Sciau, P.; Noé, L.; Colomban, P. Metal nanoparticles in contemporary potters' master pieces: Lustre and red "pigeon blood" potteries as models to understand the ancient pottery. Ceram. Int. 2016, 42, 15349-15357. [CrossRef]

36. Liu, C.; Yen, M.; Han, A.; Li, J. Structural analysis and characterization of doped spinel $\mathrm{Co}_{2-x} \mathrm{M}_{x} \mathrm{TiO}_{4}$ $\left(\mathrm{M}=\mathrm{Mg}^{2+}, \mathrm{Mn}^{2+}, \mathrm{Ni}^{2+}, \mathrm{Cu}^{2+}\right.$, and $\left.\mathrm{Zn}^{2+}\right)$ coated mica composite pigments. Ceram. Int. 2015, 41, 5537-5546. [CrossRef]

37. Jing, C.; Xiaobo, S.; Bing, H. The preparation and characteristics of cobalt blue colored mica titania pearlescent pigments by microemulsions. Dyes Pigment. 2007, 75, 766-769. [CrossRef]

38. Bayat, N.; Baghshahi, S.; Alizadeh, P. Synthesis of white pearlescent pigments using the surface response method of statistical analysis. Ceram. Int. 2008, 34, 2029-2035. [CrossRef]

39. Ryu, Y.C.; Kim, T.G.; Seo, G.-S.; Park, J.H.; Suh, C.S.; Park, S.-S.; Hong, S.-S.; Lee, G.D. Effect of substrate on the phase transformation of $\mathrm{TiO}_{2}$ in pearlescent pigment. J. Ind. Eng. Chem. 2008, 14, 213-218. [CrossRef]

40. Siligardi, C.; Montecchi, M.; Montorsi, M.; Pasquali, L. Ceria-containing frit for luster in modern ceramic glaze. J. Am. Ceram. Soc. 2010, 93, 2545-2550. [CrossRef] 
41. Dondi, M.; Zanelli, C.; Ardit, M.; Cruciani, G.; Mantovani, L.; Tribaudino, M.; Andreozzi, G.B. Ni-free, black ceramic pigments based on $\mathrm{Co}-\mathrm{Cr}-\mathrm{Fe}-\mathrm{Mn}$ spinels: A reappraisal of crystal structure, colour and technological behaviour. Ceram. Int. 2013, 39, 9533-9547. [CrossRef]

42. He, X.; Wang, F.; Liu, H.; Niu, L.; Wang, X. Synthesis and color properties of the $\mathrm{TiO}_{2} @ \mathrm{CoAl}_{2} \mathrm{O}_{4}$ blue pigments with low cobalt content applied in ceramic glaze. J. Am. Ceram. Soc. 2018, 101, 2578-2588. [CrossRef]

43. Chen, S.; Cheng, M.; Lang, Y.; Wei, H.; Wang, C. Synthesis and chromatic properties of zircon encapsulated ceramic black pigment with carbon sphere as carbon source. J. Eur. Ceram. Soc. 2018, 38, 2218-2227. [CrossRef]

44. Romero, M.; Rincón, J.M. Surface and bulk crystallization of glass-ceramic in the $\mathrm{Na}_{2} \mathrm{O}-\mathrm{CaO}-\mathrm{ZnO}-$ $\mathrm{PbO}-\mathrm{Fe}_{2} \mathrm{O}_{3}-\mathrm{Al}_{2} \mathrm{O}_{3}-\mathrm{SiO}_{2}$ system derived from a goethite waste. J. Am. Ceram. Soc. 1999, 82, 1313-1317. [CrossRef]

45. Montins Nebot, V.; Cabrera Ibáñez, M.J.; Solsona Monzonis, D.; Sala Iniesta, J.M. Recubrimiento Para Cuerpos Cerámicos. ES2415984B1, 20 May 2014.

46. Echarri-Iribarren, V.; González-Avilés, A.B.; Viqueira-Pérez, V. Iridescent techniques in ceramics: Physico-chemical analysis and colorimetric characterization of the headquarters of the botín foundation in santander. Appl. Sci. 2019, 9, 1521. [CrossRef]

47. ASTM. Standard Test Method for Multiangle Color Measurement of Metal Flake Pigmented Materials; ASTM International: West Conshohocken, PA, USA, 2014; pp. E2194-E2214. Available online: http://www.astm.org (accessed on 17 March 2019).

48. Klein, G.A. Industrial Color Physics; Springer: New York, NY, USA, 2010.

49. Chorro, E.; Perales, E.; Burgos, F.J.; Gómez, O.; Vilaseca, M.; Viqueira, V.; Pujol, J.; Martínez-Verdú, F.M. The minimum number of measurements for colour, sparkle, and graininess characterisation in gonio-apparent panels. Coloration Technol. 2015, 131, 303-309. [CrossRef]

50. Ferrero, A.; Perales, E.; Rabal, A.; Campos, J.; Martínez-Verdú, F.M.; Chorro, E.; Pons, A. Color representation and interpretation of special effect coatings. J. Opt. Soc. Am. A 2014, 32, 436-447. [CrossRef] [PubMed]

51. Pastor, J.Y.; Poza, P.; LLorca, J.; Peña, J.I.; Merino, R.I.; Orera, V.M. Mechanical properties of directionally solidified $\mathrm{Al}_{2} \mathrm{O}_{3}-\mathrm{ZrO}_{2}\left(\mathrm{Y}_{2} \mathrm{O}_{3}\right)$ Eutectics. Mater. Sci. Eng. A 2001, 308, 241-249. [CrossRef]

52. Merino, R.I. Cerámicas eutécticas solidificadas direccionalmente para fotónica y electrocerámica. Rev. Real Acad. Cienc. 2006, 61, 47-86.

53. Dahl, G.T.; Krueger, J.D.; Döring, S.; Weller, H.; Vossmeyer, T. Seeded growth synthesis of Zirconia@Gold particles in aqueous solution. Nanomaterials 2020, 10, 1197. [CrossRef]

54. Solís Pinargote, N.W.; Smirnov, A.; Peretyagin, N.; Seleznev, A.; Peretyagin, P. Direct Ink writing technology (3D printing) of graphene-based ceramic nanocomposites: A review. Nanomaterials 2020, 10, 1300. [CrossRef]

55. Gajadhur, M.; Łuszczyńska, A. Influence of pearlescent pigments on light-fastness of water-based flexographic inks. Dyes Pigment. 2017, 138, 119-128. [CrossRef]

56. Florez Miguel, R.; Crespillo, L.; He, X.; White, T.W.; Hilmas, G.; Fahrenholtz, W.; Graham, J. The irradiation response of $\mathrm{ZrC}$ ceramics under $10 \mathrm{MeV} \mathrm{Au}^{3+}$ ion irradiation at $800^{\circ} \mathrm{C}$. J. Eur. Ceram. Soc. 2020, 40, 1791-1800. [CrossRef]

57. Lei, B.; Qin, W.; Kang, G.; Peng, C.; Wu, J. Modeling and evaluation for encapsulation efficiency of zircon-based heteromorphic encapsulation pigments. Dyes Pigment. 2015, 112, 245-254. [CrossRef]

(C) 2020 by the authors. Licensee MDPI, Basel, Switzerland. This article is an open access article distributed under the terms and conditions of the Creative Commons Attribution (CC BY) license (http://creativecommons.org/licenses/by/4.0/). 